\title{
Formation of Aqueous Biphasic Systems with an Ionic Liquid Induced by Metallic Salts: Nanoscopic Views from Molecular Dynamics Simulations
}

\author{
Rachel Schurhammer and Georges Wipff*i) \\ Chimie de la Matière Complexe, UMR CNRS 7140, 1, rue B. Pascal, 67000 Strasbourg, France
}

Supporting Information

\begin{abstract}
The formation of aqueous biphasic systems (ABSs) based on aqueous ionic liquid (IL)/salt mixtures has been investigated via molecular dynamics simulations (with IL butyl-methyl-imidazolium triflate; salts $\mathrm{NaCl}, \mathrm{CsCl}, \mathrm{SrCl}_{2}$, and $\left.\mathrm{EuCl}_{3}\right)$. The analysis of ion distributions, solvation, and mutual interactions during the dynamics reveals the heterogeneity of all solutions due to ion segregation into mutually exclusive IL and salt domains, even in monophasic solutions ("ionic sociology"). Ion segregation and ABS formation are found to increase with (i) the salt content and (ii) the IL content, (iii) in the order $\mathrm{Na}^{+}<\mathrm{Sr}^{2+}<\mathrm{Eu}^{3+}$, and (iv) when the IL ion "polarity" is diminished, following experimental trends. The structuration of the solution is

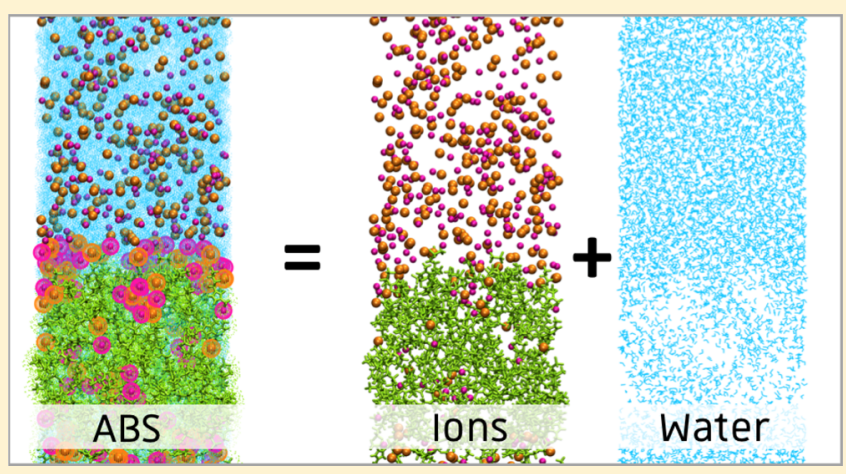
rationalized as a synergistic water transfer from the best donating ion pair (first hydration shell of hydrophobic moieties of IL ions) to the best accepting pair $\left(\mathrm{M}^{n+}\right.$ and $\mathrm{Cl}^{-}$ions, beyond their first shell). In ABSs, the IL- and salt-containing phases are linked by a well-defined "interface" that decreases in width when $\mathrm{MCl}_{n}$ becomes more hydrophilic and/or more concentrated. In the IL-rich phase of ABSs, the hydration of IL ions and their mutual interactions are shown to be similar to those displayed at aqueous interfaces.
\end{abstract}

\section{INTRODUCTION}

Aqueous biphasic systems (ABSs), based on water as a single solvent, play an important role in many domains such as the separation, extraction, and purification of biological systems or the treatment of polluted water. ${ }^{1,2}$ Generally, ABSs are formed by mixing two aqueous phases containing either two polymers or a polymer plus a salting-out inducing salt or specific saltsalt combinations at appropriate concentrations and temperature. An interesting class of $\mathrm{ABS}$ is based on aqueous solutions of ionic liquids (ILs) to which salting-out inorganic salts can be added to promote separation into two phases. In practice, such IL-based ABSs have many advantages like low viscosity, resistance to emulsification, quick phase separation, high extraction capabilities, and benefit from a potentially "infinite" panoply of IL components designed for a given use. In 2003, Rogers and colleagues reported that addition of a water-structuring salt, $\mathrm{K}_{3} \mathrm{PO}_{4}$, to an aqueous concentrated solution of 1-butyl-3-methylimidazolium chloride induced the formation of an upper IL-rich phase and a lower $\mathrm{K}_{3} \mathrm{PO}_{4}$-rich phase, ${ }^{3}$ as for classical poly(ethylene glycol) (PEG)-/salt-based ABSs. ${ }^{4,5}$ Since then, many combinations of IL components and salting-out agents have been studied, both to define the underlying driving forces and to establish general guidelines for specific purposes. ${ }^{2,6,7}$ Similar salt-specific effects have also been observed with the related biphasic extraction systems based on hydrophobic ILs. ${ }^{8}$ Generally, for a given $\mathrm{M}_{x} \mathrm{X}_{y}$ salt, $\mathrm{ABS}$ formation is enhanced by the size and hydrophobicity (or reduced hydrophilicity) of ionic components of the $\mathrm{IL}^{9,10}$ and by the hydrophilic and salting-out character of the dissolved $\mathrm{M}_{x} \mathrm{X}_{y}$ salt, ${ }^{11-14}$ following the Hofmeister ion series ${ }^{15}$ whose interpretation in terms of thermodynamic and structural features remains controversial. ${ }^{11,16,17}$ The hydrophilic/hydrophobic character ${ }^{18,19}$ is often related to the Gibbs free energy of ion hydration ${ }^{20}$ and to concepts like structure breaking ("chaotropic")/making ("cosmotropic") features in water. ${ }^{18,21-25}$ Recently, Shahriari et al. ${ }^{14}$ correlated the amount of IL necessary to form an ABS and the entropy of hydration of the salt ions, drawing the implication of a dominant entropic driving force for ABS formation, as for hydrophobic ILs ${ }^{11,26,27}$ or polymer-based $\mathrm{ABSs},{ }^{28,29}$ presumably due to the formation of "water-ion complexes". Insights into ion solvation and into their mutual interactions have been gained from NMR spectroscopy and simulations in aqueous salt solutions containing IL ions, ${ }^{11,27,30,31}$ but these may not suffice to fully describe the "organization" of the solution, the distribution of all ions, and finally the formation of ABSs in conditions when it occurs. Likewise, the nature of the aqueous-aqueous interface of ABSs has neither been characterized so far nor compared,

Received: July 2, 2018

Revised: October 17, 2018

Published: October 18, 2018 


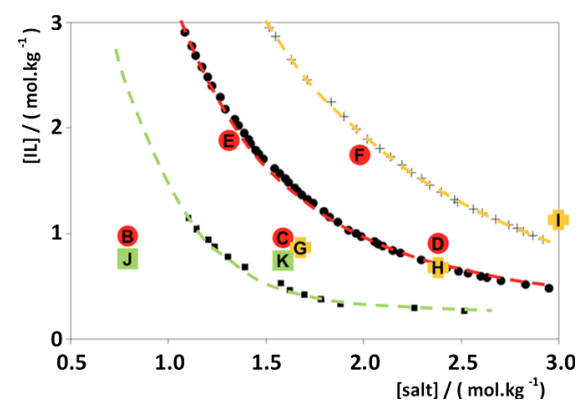

Figure 1. Ternary phase diagram of the $[\mathrm{BMI}][\mathrm{TfO}] \mathrm{IL}$, water, and $\mathrm{MCl}_{n}$ salts: $\mathrm{CsCl}(+), \mathrm{NaCl}(\bullet)$, and $\mathrm{SrCl}_{2}(\boldsymbol{\square})$, adapted from ref 14 . The simulated solutions are marked $\mathrm{B}$ to $\mathrm{F}(\mathrm{NaCl}$; red), $\mathrm{G}$ to I ( $\mathrm{CsCl}$; yellow), and $\mathrm{J}$ and $\mathrm{K}\left(\mathrm{SrCl}_{2}\right.$; green).

for instance to aqueous interfaces with hydrophobic (waterimmiscible) ILs. ${ }^{32-37}$

This led us to consider a well-documented case and to explore by molecular dynamics (MD) simulations to what extent homogeneous aqueous mixtures of IL and dissolved inorganic $\mathrm{MCl}_{n}$ salts separate at the nanoscopic level and to analyze what are the related solvation patterns and driving forces. The selected $\mathrm{IL}$, based on $\mathrm{BMI}^{+}$(butyl-methylimidazolium ${ }^{+}$) and $\mathrm{TfO}^{-}$(triflate $\mathrm{CF}_{3} \mathrm{SO}_{3}^{-}$) ions, is readily soluble in water, as are the $\mathrm{MCl}_{n}$ salts. Their ternary diagrams, adapted from ref 14, are shown in Figure 1; the systems at the righthand side of a curve are biphasic and those of the left-hand side are monophasic, while a given curve corresponds to the intermediate states ("cloud points"). Here, the ABS formation increases with the IL and/or salt content and in the order $\mathrm{CsCl}$ $<\mathrm{NaCl}<\mathrm{SrCl}_{2}$, that is, with the $\mathrm{M}^{n+}$ charge and hydrophilicity. The simulated solutions are marked $\mathrm{B}$ to $\mathrm{K}$ in Figure 1. Additionally, a "neat" IL aqueous solution A (without added salt) was studied as a reference, as well as the $\mathrm{EuCl}_{3}$ solutions $\mathrm{L}$ to $\mathrm{P}$, expected to display the strongest ABSpromoting effect. Their characteristics are given in Tables 1

Table 1. Characteristics of the Simulated Solutions A to $\mathbf{P}^{a}$

\begin{tabular}{|c|c|c|c|c|c|}
\hline & $\begin{array}{l}\text { IL number of } \\
\text { pairs }\end{array}$ & \multicolumn{2}{|c|}{$\begin{array}{c}\mathrm{MCl}_{n} \text { salt } \\
\text { number of pairs }\end{array}$} & $\begin{array}{l}{[\mathrm{IL}]} \\
\mathrm{mol} \mathrm{kg}\end{array}$ & $\begin{array}{l}{\left[\mathrm{MCl}_{n}\right]} \\
\mathrm{mol} \mathrm{kg}^{-1}\end{array}$ \\
\hline A & 148 & 0 & & 1.03 & 0.00 \\
\hline $\mathrm{A} 2$ & 592 & 0 & & 1.03 & 0.00 \\
\hline B & 148 & 148 & $\mathrm{NaCl}$ & 0.97 & 0.79 \\
\hline $\mathrm{C}$ & 148 & 296 & $\mathrm{NaCl}$ & 0.92 & 1.59 \\
\hline $\mathrm{D}$ & 148 & 444 & $\mathrm{NaCl}$ & 0.87 & 2.38 \\
\hline $\mathrm{E}$ & 296 & 296 & $\mathrm{NaCl}$ & 1.83 & 1.29 \\
\hline $\mathrm{F}$ & 296 & 444 & $\mathrm{NaCl}$ & 1.74 & 1.94 \\
\hline $\mathrm{D} 2$ & 592 & 1776 & $\mathrm{NaCl}$ & 0.87 & 2.38 \\
\hline G & 148 & 296 & $\mathrm{CsCl}$ & 0.76 & 1.59 \\
\hline $\mathrm{H}$ & 148 & 444 & $\mathrm{CsCl}$ & 0.68 & 2.38 \\
\hline I & 296 & 700 & $\mathrm{CsCl}$ & 1.13 & 3.05 \\
\hline $\mathrm{J}$ & 148 & 148 & $\mathrm{SrCl}_{2}$ & 0.88 & 0.79 \\
\hline $\mathrm{K}$ & 148 & 296 & $\mathrm{SrCl}_{2}$ & 0.77 & 1.59 \\
\hline $\mathrm{L}$ & 148 & 296 & $\mathrm{EuCl}_{3}$ & 0.67 & 1.59 \\
\hline M & 148 & 148 & $\mathrm{EuCl}_{3}$ & 0.81 & 0.79 \\
\hline $\mathrm{N}$ & 148 & 74 & $\mathrm{EuCl}_{3}$ & 0.91 & 0.40 \\
\hline $\mathrm{O}$ & 148 & 50 & $\mathrm{EuCl}_{3}$ & 0.94 & 0.27 \\
\hline $\mathrm{P}$ & 148 & 25 & $\mathrm{EuCl}_{3}$ & 0.98 & 0.13 \\
\hline
\end{tabular}

${ }^{a}$ Unless otherwise specified, the box is "standard" and contains 8000 $\mathrm{H}_{2} \mathrm{O}$; the "big" box (A2 and D2 systems) contains $32000 \mathrm{H}_{2} \mathrm{O}$. An extended version of the table is given in Table S1. and S1 of the Supporting Information. The simulations were conducted in a consistent manner, in terms of water and ion content and of computational protocol, starting from aqueous solutions of randomly dispersed IL and salt ions (see e.g., Figure S1). During the dynamics, ions segregated and, in some cases, separated into two distinct phases (ABS formation), affording microscopic insights into the ion segregation and solution reorganization presented and analyzed below.

\section{METHODS}

The solutions were simulated by classical MD simulations using the AMBER $16^{38}$ software, in which the potential energy $\mathrm{U}$ is empirically represented by a sum of bond and angle harmonic deformations, of dihedral torsions, and by pairwise additive 1-6-12 (electrostatic + van der Waals) interactions between nonbonded atoms (eq 1 )

$$
\begin{aligned}
U= & \sum_{\text {bonds }} k_{\mathrm{r}}\left(r-r_{0}\right)^{2}+\sum_{\text {angles }} k_{\theta}\left(\theta-\theta_{0}\right)^{2} \\
& +\sum_{\text {dihedrals }} k_{\phi}\left[1+\cos \left(n \phi+\phi_{0}\right)\right] \\
& +\sum_{\text {atom } i} \sum_{j \neq i} 4 \varepsilon_{i, j}\left[\left(\frac{\sigma_{i, j}}{r_{i, j}}\right)^{12}-\left(\frac{\sigma_{i, j}}{r_{i, j}}\right)^{6}\right]+\sum_{\text {atom } i} \sum_{j \neq i} \frac{q_{i} q_{j}}{\varepsilon_{0} r_{i, j}}
\end{aligned}
$$

Solute and solvent atom pairs $i$ and $j$ display Coulomb interactions via their charges $q_{i}$ and $q_{j}$, respectively. Cross terms in van der Waals interactions were constructed using the Lorentz-Berthelot rules.

Water was represented with the TIP3P model. ${ }^{39}$ For the ion parameters, we used the consistent $\mathrm{Na}^{+}, \mathrm{Cs}^{+}$, and $\mathrm{Cl}^{-}$values from Joung and Cheatham et $\mathrm{al}^{40}$ and $\mathrm{Sr}^{2+}$ and $\mathrm{Eu}^{3+}$ values from refs 41 and 42, respectively. The $\mathrm{BMI}^{+}$parameters are from de Andrade et $\mathrm{al}^{43}$ and the $\mathrm{TfO}^{-}$ones are from Baaden et al. ${ }^{44} \mathrm{~A}$ first set of simulations, conducted with integral \pm 1 charges on IL ions ( $\mathrm{IL}^{ \pm 1}$ model), produced some instances in conflict with experiment. We thus decided to use reduced charges of \pm 0.9 ( $\mathrm{IL}^{ \pm 0.9}$ model with atomic charges scaled by 0.9 ), as in previous work on IL/water biphasic mixtures. ${ }^{45-48}$ Formally reducing the ionic charges to a degree mimics the anion to cation electron transfer in the condensed IL phases (e.g., $[\mathrm{BMI}]\left[\mathrm{PF}_{6}\right]$ or $\left.[\mathrm{BMI}]\left[\mathrm{Tf}_{2} \mathrm{~N}\right]\right)^{35,49}$ and also better accounts for the solubility of IL ions in an aqueous phase. ${ }^{46}$ The 1-4 van der Waals and 1-4 Coulombic interactions were scaled down by 2.0 and 1.2, respectively. The solutions were simulated with three-dimensional (3D) periodic boundary conditions, using an atom-based cutoff of 12 A for nonbonded interactions and correcting for the long-range electrostatics by using the Ewald summation method. The characteristics of all simulated systems are given in Tables 1 and $S 1$ of the Supporting Information. The MD simulations were performed at $300 \mathrm{~K}$ starting with random velocities. The temperature was monitored via a coupling to a thermal bath using the Berendsen algorithm ${ }^{50}$ with a relaxation time of 0.2 ps. In the $(N P T)$ simulations, the pressure was similarly coupled to a barostat with a relaxation time of 0.2 ps. A time step of 2 fs was used to integrate the equations of motion via the Verlet leapfrog algorithm.

For each system, a "random" mixture of $\mathrm{MCl}_{n}$ and IL ions $\left(\mathrm{M}^{n+}, \mathrm{Cl}^{-}, \mathrm{BMI}^{+}\right.$, and $\left.\mathrm{TfO}^{-}\right)$was prepared in a box of 8000 or $32000 \mathrm{H}_{2} \mathrm{O}$ molecules ("standard" box and "big" box, 
respectively). After 1000 steps of energy minimization, $0.25 \mathrm{~ns}$ of dynamics was performed to allow the solvent to relax around the solute. This was followed by a dynamics run of 0.25 ns at constant volume and of $1 \mathrm{~ns}$ at a constant pressure of 1 atm. Note that the relaxed box sizes may somewhat differ from one system to the other (see Table S1 of the Supporting Information). Furthermore, in some cases, some salt reorganization already occurred at this preparation stage. The evolution of the mixture was then followed for $500 \mathrm{~ns}$ of dynamics (NVT ensemble), sometimes extended up to 1000 ns.

2.1. Analysis of Results. The trajectories were analyzed using our MDS software. ${ }^{51}$ Snapshots were drawn with the VMD software. ${ }^{52}$ The radial density functions (RDFs) were calculated, unless otherwise specified, between selected atoms, $\mathrm{N}_{\text {butyl }}$ or $\mathrm{C}_{\mathrm{TFO}}$ of IL ions, $\mathrm{M}^{n+}$ or $\mathrm{Cl}^{-}$ions, and $\mathrm{O}_{\mathrm{H}_{2} \mathrm{O}}, \mathrm{H}_{\mathrm{H}_{2} \mathrm{O}}$ atoms. The distributions of $\mathrm{M}^{n+}$ and $\mathrm{Cl}^{-}, \mathrm{BMI}^{+}$and $\mathrm{TfO}^{-}$ions, $\mathrm{H}_{2} \mathrm{O}$ molecules in the box, and the corresponding massweighted densities $d$ were calculated along the $z$-coordinate and averaged over different time periods (typically the last 5 or $50 \mathrm{~ns}$ ) specified in the relevant figures. The total potential energy $E_{\text {pot }}$ and interactions between selected neutral groups (IL ions, $\mathrm{MCl}_{n}$ ions, and water) were calculated using Ewald summation. To simply "measure" the extent of ion segregation and phase separation at a given time, a "demixing index" $\xi_{\text {demix }}$ defined by $1 / \xi_{\text {demix }}=1 / d_{\mathrm{IL}}+1 / d_{\text {wat }}$, where $d_{\mathrm{IL}}$ and $d_{\text {wat }}$ are the densities of IL and water, respectively, was used, as in previous work, ${ }^{46,53}$ in "nanoboxes" of $0.8 \times 0.8 \times 1.0 \mathrm{~nm}^{3}$ volume. The simulation box was thus split into such nanoboxes, and the corresponding normalized $\xi_{\text {demix }}$ was averaged over all boxes. Thus, in principle, $\xi_{\text {demix }}$ ranges from 1 (for randomly dispersed components) to 0 (for two juxtaposed immiscible components, for example, water and "oil").

\section{RESULTS}

In the following, we first describe the "neat IL" aqueous solution $\mathrm{A}$ as a reference. The effects of salt concentration (mainly focused on $\mathrm{NaCl}$ ) and of IL concentration are presented in Section 3.2. In Section 3.3, we compare the different $\mathrm{MCl}_{n}$ salts $\left(\mathrm{CsCl}, \mathrm{NaCl}, \mathrm{SrCl}_{2}\right.$, and $\mathrm{EuCl}_{3}$ ) at the same metal and IL content. Ion/ion interactions and hydration in the above series are then analyzed and compared to the purely aqueous solutions (Section 3.4). Although all simulations have been conducted with both $\mathrm{IL}^{ \pm 0.9}$ and $\mathrm{IL}^{ \pm 1}$ models, we restrict the presentation of $\mathrm{IL} /$ salt mixtures (Sections 3.2-3.4) to the $\mathrm{IL}^{ \pm 0.9}$ results. The $\mathrm{IL}^{ \pm 1}$ results are given in the Supporting Information. The ionic content of a simulated box is noted in short, for example, $128 \mathrm{IL}^{ \pm 0.9} / 296$ $\mathrm{NaCl}$ for $128 \mathrm{BMI}^{+} \mathrm{TfO}^{-}\left(\mathrm{IL}^{ \pm 0.9}\right.$ charges$)$ and $296 \mathrm{Na}^{+} \mathrm{Cl}^{-}$salt ions. The evolution of the demixing index $\xi_{\text {demix }}$ during the first $100 \mathrm{~ns}$ of the different dynamics is plotted in Figure 2 for the $\mathrm{NaCl}$ - and for the $\mathrm{MCl}_{n}$-containing solutions, and the final average $\xi_{\text {demix }}$ values are collected in Table 2 .

3.1. "Neat" Aqueous IL Solution is Heterogeneous Due to Hydrophobic Contacts. Solution A was simulated at the same IL and water content $\left(148 \mathrm{BMI}^{+} \mathrm{TfO}^{-}, 8000 \mathrm{H}_{2} \mathrm{O}\right.$ per box) as in salt-containing ones. The main results are shown in Figures 3 and S2 of the Supporting Information. As seen in the final snapshots, in the absence of the $\mathrm{MCl}_{n}$ salt, the solution is monophasic and the IL ions are dispersed in the box. The water density profile along the $z$-axis of the box, averaged over the last $100 \mathrm{~ns}$, is flat. The $\mathrm{BMI}^{+}$and $\mathrm{TfO}^{-}$density curves are
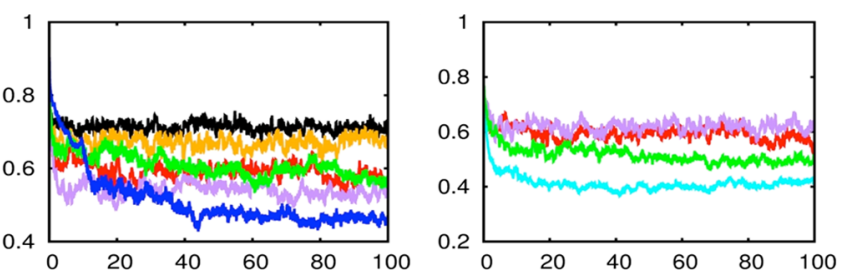

Figure 2. $\mathrm{IL}^{ \pm 0.9}$ salt solutions: demixing index $\xi_{\text {demix }}$ as a function of time (0 to $100 \mathrm{~ns})$. Left: $\mathrm{NaCl}$ solutions A (148/0 black), B (148/148 orange), C (148/296 red), D (148/444 purple), E (296/296 green), F (296/444 blue). Right: MCln solutions C ( $\mathrm{NaCl}$ red), G ( $\mathrm{CsCl}$ purple), $\mathrm{K}$ ( $\mathrm{SrCl}_{2}$ green), $\mathrm{L}\left(\mathrm{EuCl}_{3}\right.$ cyan).

quasi-superimposable but not flat, indicative of IL heterogeneities. This feature is also visible by averaging over different time periods: $10-200,100-200,150-200$, or $190-200 \mathrm{~ns}$ (Figure S3 of the Supporting Information).

According to the RDFs (see integration numbers in S2 of the Supporting Information), the $\mathrm{BMI}^{+}$and $\mathrm{TfO}^{-}$ions are mostly separated and well hydrated, by ca. 8-10 $\mathrm{H}_{2} \mathrm{O}$ molecules in their first shell. They also sometimes form loose pairs, corresponding to a first peak in the BMI $\cdots$ TfO RDFs that integrates to 0.32 (within $5 \AA$ ). Of relevance for the formation of $\mathrm{ABSs}$, we note that the shortest $\mathrm{BMI}^{+} . . \mathrm{TfO}^{-}$contacts do not correspond to electrostatic but to hydrophobic attractions (between $\mathrm{CF}_{3}(\mathrm{TfO})$ atoms and either the $\pi$-ring or the butyl chain of $\mathrm{BMI}^{+}$), whereas the more polar $\mathrm{SO}_{3}{ }^{-}$and ring(imidazolium) $)^{+}$moieties are well hydrated and separated. Hydrophobic contacts are likewise observed between $\mathrm{TfO}^{-}$ anions (via their $\mathrm{CF}_{3}(\mathrm{TfO})$ groups; see snapshots and the $\mathrm{C}_{\mathrm{TfO}} \cdots \mathrm{C}_{\mathrm{TfO}} \mathrm{RDF}$ that integrates to 0.27 ), in spite of their Coulombic repulsions. Similar features are observed in the "standard" (A) and "big" boxes (A2), pointing to the critical role of hydrophobic interactions for IL ion association. On the other hand, there are no $\pi-\pi$ stacking contacts between imidazolium cations.

Comparing now the $\mathrm{IL}^{ \pm 0.9}$ to the $\mathrm{IL}^{ \pm 1}$ models (Figure S2 and Table S2 of the Supporting Information), we note that there is a little bit more $\mathrm{BMI}^{+} \ldots \mathrm{TfO}^{-}$and $\mathrm{TfO}^{-} \ldots \mathrm{TfO}^{-}$pairing (and hence presumably more IL association) with the less "polar" $\mathrm{IL}^{ \pm 0.9}$ one than with the $\mathrm{IL}^{ \pm 1}$ one, whereas the $\mathrm{IL}^{ \pm 0.9}$ ions are somewhat less well hydrated than the $\mathrm{IL}^{ \pm 1}$ ones.

3.2. Adding $\mathrm{NaCl}, \mathrm{CsCl}$, or $\mathrm{SrCl}_{2}$ at Different Concentrations to an Aqueous Solution of $\mathrm{BMI}^{+} \mathrm{TfO}^{-}$ Ions: from Mixed to Separated Phases. In this section, we first compare solutions at a fixed IL content $\left(148 \mathrm{BMI}^{+} \mathrm{TfO}^{-}\right.$ per box) and different $\mathrm{MCl}_{n}$ salt concentrations and then solutions at different IL concentrations, depicted with the $\mathrm{IL}^{ \pm 0.9}$ model.

3.2.1. Effect of Salt Concentration. Three $\mathrm{NaCl}$ solutions (B, C, and D, of salt/IL ratios of 1:1, 2:1, and 3:1, respectively) were first considered. As seen from final snapshots (Figure 4) and average density curves (Figure 5), all three are heterogeneous and display increased ion segregation from solutions $\mathrm{A}$ (without $\mathrm{NaCl}$ ) to $\mathrm{B}$ and from $\mathrm{B}$ to $\mathrm{D}$. Accordingly, the $\xi_{\text {demix }}$ index decreases in the A-D series: $\approx 0.74,0.65,0.62$, and 0.48 , respectively.

In solution $\mathrm{D}$, the ions partition into two well-defined slabs, indicating phase separation. At $500 \mathrm{~ns}$, the salt slab contains the majority of the $\mathrm{Na}^{+}$and $\mathrm{Cl}^{-}$ions but only ca. $3 \mathrm{IL}$ ion pairs. In contrast, the IL slab contains only ca. $10 \mathrm{NaCl}$ ion pairs but still much water $\left(\approx 1200\right.$ of the $8000 \mathrm{H}_{2} \mathrm{O}$ molecules $)$, supporting the view that the two juxtaposed phases are mainly 
Table 2. Final Demixing Index $\xi_{\text {demix }}$ for Systems A to L (Averages during the Last 10 ns; Fluctuations are about 0.02 )

\begin{tabular}{ccccccccccccc} 
solution & A & B & C & D & E & F & G & H & I & J & K & L \\
$\mathrm{IL}^{ \pm 1}$ & 0.73 & 0.74 & 0.70 & 0.64 & 0.71 & 0.65 & 0.71 & 0.68 & 0.63 & 0.70 & 0.65 & 0.45 \\
$\mathrm{IL}^{ \pm 0.9}$ & 0.74 & 0.65 & 0.62 & 0.48 & 0.56 & 0.47 & 0.61 & 0.53 & 0.41 & 0.58 & 0.49 & 0.42 \\
\hline
\end{tabular}

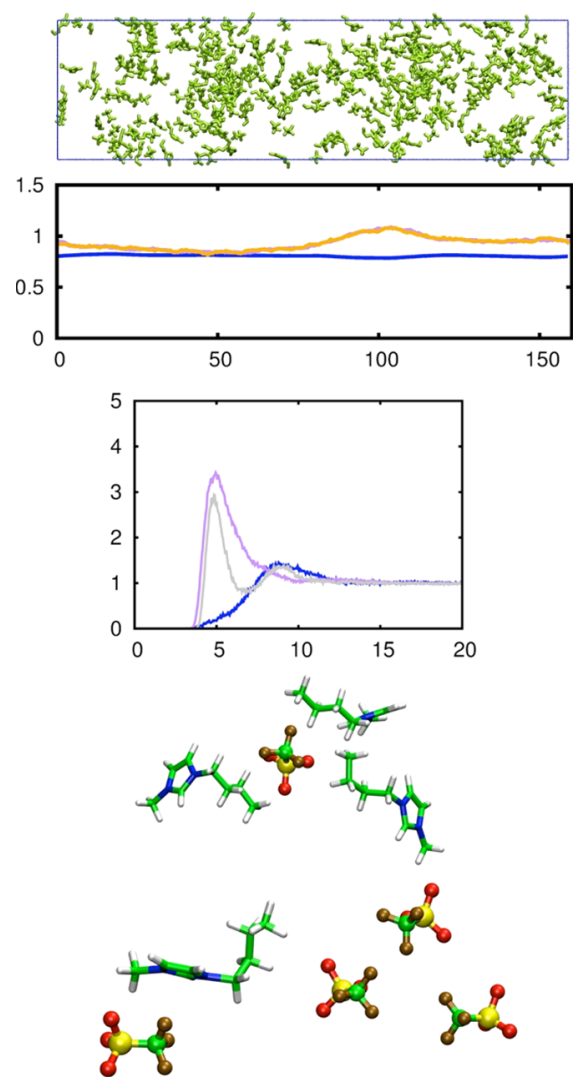

Figure 3. Neat IL aqueous solution A ( $\mathrm{IL}^{ \pm 0.9}$ model). Snapshot at 200 ns with the IL only (line 1). Line 2: Average densities along the $z$-axis of the box (distances in $\AA$ ) during $100-200 \mathrm{~ns}\left(\mathrm{BMI}^{+}\right.$orange, $\mathrm{TfO}^{-}$ purple, water blue); $\mathrm{C}_{\mathrm{TfO}}, \mathrm{N}_{\mathrm{Buty}}$ and $\mathrm{O}_{\mathrm{H}_{2} \mathrm{O}}$ are the reference centers.

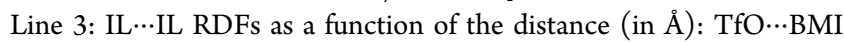

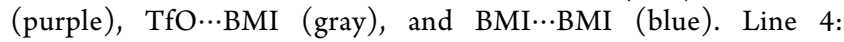
Snapshots of IL...IL contacts. An extended version of the figure, including $\mathrm{IL}^{ \pm 1}$ results is given in Figure S2. The density curves averaged over different time periods are shown in Figures 5 and S3.

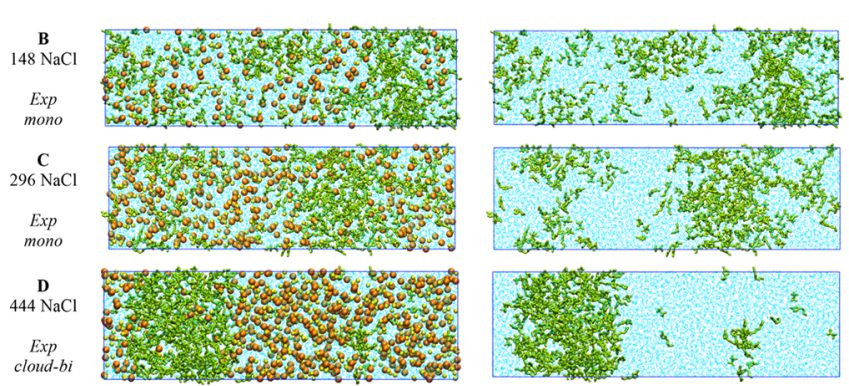

Figure 4. $148[\mathrm{BMI}][\mathrm{TfO}]^{ \pm 0.9} / \mathrm{NaCl}$ solutions B-D. Snapshots after $500 \mathrm{~ns}$, with either all components (left) or with $\mathrm{NaCl}$ hidden (right). Color codes: IL ions green, water cyan, $\mathrm{Cl}^{-}$orange, and $\mathrm{Na}^{+}$yellow.

aqueous. This picture is consistent with the density curves: IL and salt (or water) densities, averaged over the last $5 \mathrm{~ns}$, display anticorrelated plateaus. The IL density drops close to zero in the $\mathrm{NaCl} \mathrm{slab}$, as does the $\mathrm{NaCl}$ density in the IL slab. Note that the distribution curves of individual $\mathrm{Na}^{+}$and $\mathrm{Cl}^{-}$ ions are superimposable, as are the $\mathrm{BMI}^{+}$and $\mathrm{TfO}^{-}$curves (Figure S5 of the Supporting Information), indicating that each phase is overall neutral, with neutral contributions of $\mathrm{Na}^{+} \mathrm{Cl}^{-}$ions and of IL ions, respectively. Densities averaged over a longer time period (50, instead of $5 \mathrm{~ns}$ ) afford the same features, but the high IL density profile becomes somewhat "bell-shaped" (Figure S4 of the Supporting Information) because of ion passage across the "interface".

In the more dilute $\mathrm{C}$ and $\mathrm{B}$ solutions, ions also segregate, without forming clear slabs, however, because the mutual IL/ $\mathrm{NaCl}$ exclusion has decreased together with the $\mathrm{NaCl}$ concentration. B is overall monophasic but contains distinct $\mathrm{NaCl}$-rich and IL-rich domains: the IL density peak (near $z \approx$ $120 \AA$ ) correlates with a minimum of salt and water densities. These domains are expected to exchange with each other at timescales longer than the simulated ones, yielding, on average, flat density curves. For solution $\mathrm{C}$, the density profiles are more "D-like" than "B-like", showing that $\mathrm{C}$, experimentally monophasic, is quite heterogeneous at the nanoscopic scale.

The effect of salt concentration is likewise observed with the $\mathrm{CsCl}$ solutions $\mathrm{G}$ and $\mathrm{H}$ (of $\mathrm{CsCl} / \mathrm{IL}$ ratios 2:1 and 3:1, respectively) or the $\mathrm{SrCl}_{2}$ solutions $\mathrm{J}$ and $\mathrm{K}$ ( of $\mathrm{SrCl}_{2} / \mathrm{IL}$ ratios $1: 1$ and $2: 1$, respectively): the $\xi_{\text {demix }}$ index decreases from 0.61 (in $\mathrm{G}$ ) to 0.53 (in $\mathrm{H}$ ) and from 0.58 (in J) to 0.49 (in $\mathrm{K}$ ). Snapshots (Figure 6) and density curves (Figure 5) also support enhanced ion segregation and phase separation when the salt gets more concentrated. For instance, in the IL domain from $\mathrm{J}$ to $\mathrm{K}$, the IL density profile becomes narrower and of higher amplitude, whereas the water content decreases. The highest IL and lowest salt densities, "bell-shaped" in J, become rather uniform in $\mathrm{K}$ where the interfacial domain is sharper, on the average. From $\mathrm{J}$ to $\mathrm{K}$, the IL density increases in the IL slab (from $\approx 0.7$ to 0.8 ), whereas the lowest $\mathrm{SrCl}_{2}$ density remains close to zero, supporting full phase separation. This contrasts with the $\mathrm{CsCl}$ solutions $\mathrm{G}$ and $\mathrm{H}$ (experimentally monophasic), where the IL density maxima correspond to a significant $\mathrm{CsCl}$ salt content, more in $\mathrm{G}$ than in $\mathrm{H}$, and the curves are rather "bell-shaped". There is thus less $\mathrm{IL} / \mathrm{salt}$ separation with $\mathrm{CsCl}$ than with $\mathrm{SrCl}_{2}$ at both concentrations, following experimental trends. ${ }^{14}$

3.2.2. Effect of IL Concentration. Phase separation increases also with the IL concentration. To investigate this feature, we considered the $\mathrm{NaCl}$ solutions $\mathrm{C}$ and $\mathrm{D}$ described above, but doubled their IL content (solutions $\mathrm{E}$ and $\mathrm{F}$, respectively). As seen in snapshots (Figure 7) and densities (Figure 5), the IL domain becomes now broader and displays a wider plateau of density. The IL density $d_{\text {IL-max }}$ is higher when $\mathrm{NaCl}$ is most concentrated $\left(\mathrm{D}\right.$ and $\mathrm{F}$ solutions: $d_{\mathrm{IL} \text {-max }} \approx 0.8$ ) than when $\mathrm{NaCl}$ is less concentrated ( $\mathrm{C}$ and $\mathrm{E}$ solutions: $d_{\mathrm{IL}-\max } \approx 0.7$ ). Regarding the $\xi_{\text {demix }}$ index, it decreases at the lower $\mathrm{NaCl}$ concentration (from 0.62 in $\mathrm{C}$ to 0.56 in $\mathrm{E}$ ), indicating enhanced phase separation. At the higher $\mathrm{NaCl}$ concentration, however, $\xi_{\text {demix }}$ remains similar $(0.48$ in $\mathrm{D}$ and 0.47 in $\mathrm{F}$ ) because both simulated solutions are biphasic.

Simultaneously increasing the IL and salt content also enhances segregation: compare the $\mathrm{CsCl}$ solution $\mathrm{G}$ (148 IL/ $296 \mathrm{CsCl})$ to I (296 IL/700 CsCl). They both contain an IL 


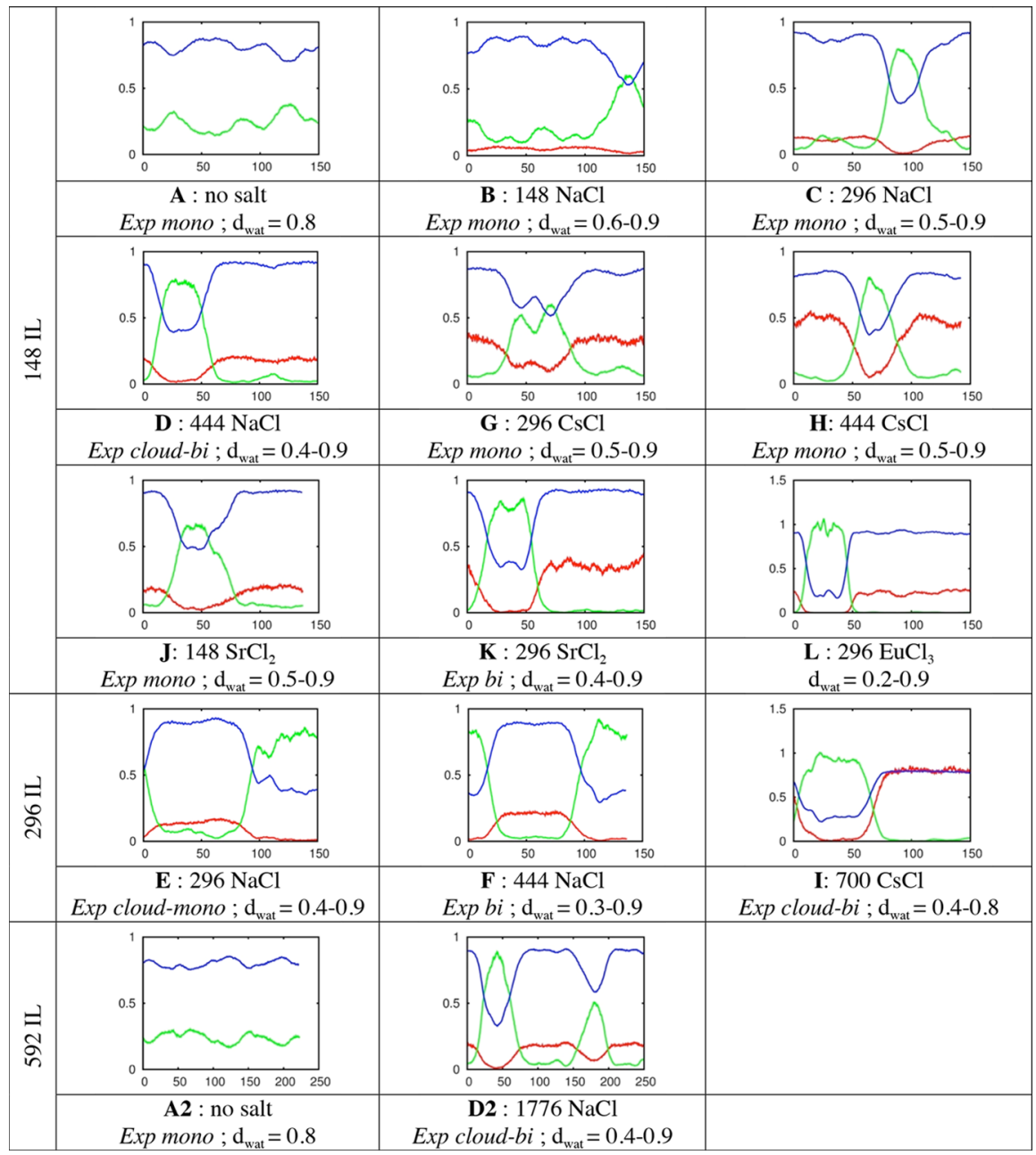

Figure 5. $\mathrm{IL}^{ \pm 0.9} / \mathrm{MCl}_{n}$ solutions: densities along the $z$-axis (in $\AA$ ) of the box, averaged over the last $5 \mathrm{~ns}$. Color codes: IL green, salt red, and water blue. For each system, the experimental phase behavior is indicated, together with the extrema of water density.

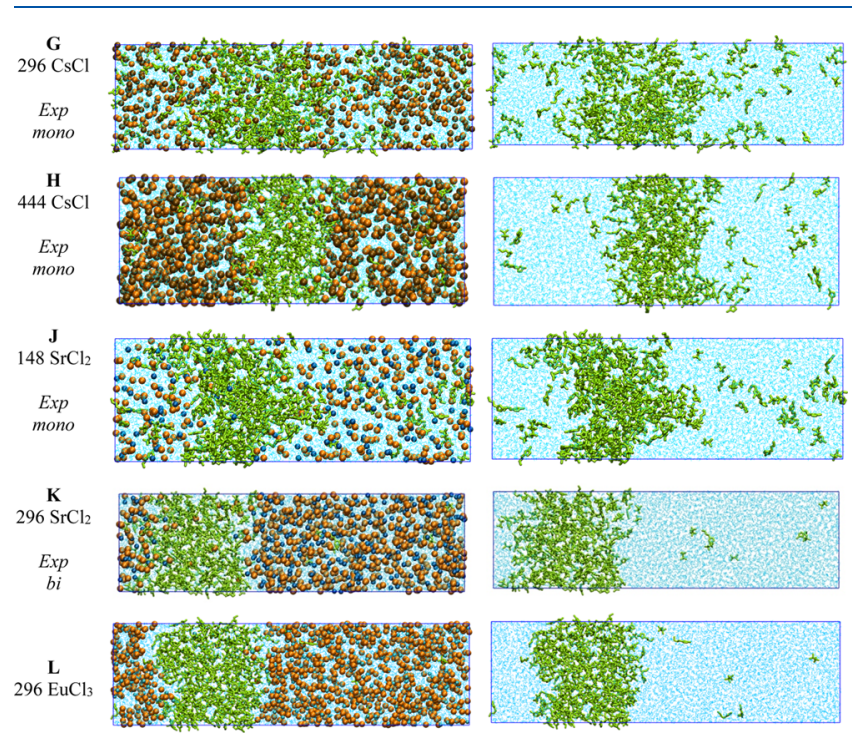

Figure 6. $148 \mathrm{IL}^{ \pm 0.9} / \mathrm{MCl}_{n}$ solutions at two $\mathrm{CsCl}$ or $\mathrm{SrCl}_{2}$ salt concentrations and $\mathrm{EuCl}_{3}$ solution L. Snapshots after $500 \mathrm{~ns}$, with either all components (left) or with salt hidden (right). Color codes: IL ions green, water cyan, $\mathrm{Cl}^{-}$orange, $\mathrm{Cs}^{+}$brown, $\mathrm{Sr}^{2+}$ dark blue, and $\mathrm{Eu}^{3+}$ blue.

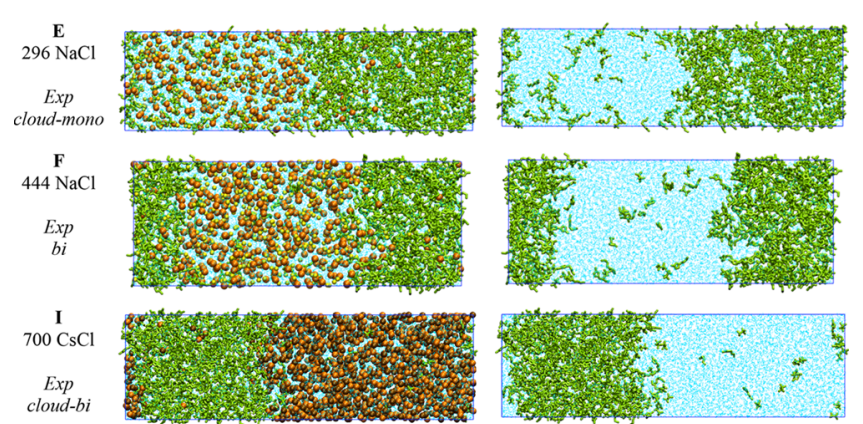

Figure 7. $296 \mathrm{IL}^{ \pm 0.9}$ solutions with $\mathrm{NaCl}$ or CsCl. Snapshots after 500 ns with either all species (left) or with the salt hidden (right). Color codes: IL green, water cyan, $\mathrm{Cl}^{-}$orange, $\mathrm{Na}^{+}$yellow, and $\mathrm{Cs}^{+}$brown.

slab, but the latter is better structured and contains less $\mathrm{CsCl}$ in I than in $G$ (Figures 5 and 7). Accordingly, from $G$ to $I$, the interface between the two phases becomes sharper, whereas $\xi_{\text {demix }}$ decreases (from 0.61 to 0.41 ).

3.3. Effect of $\mathrm{M}^{n+}$ Hardness on Phase Separation: Adding $\mathrm{NaCl}, \mathrm{CsCl}, \mathrm{SrCl}_{2}$, or $\mathrm{EuCl}_{3}$ at the Same Concentration to an Aqueous Solution of $\mathrm{BMI}^{+} \mathrm{TfO}^{-}$ lons. Let us now compare solutions of identical IL and water content to which a fixed amount of salt species $(\mathrm{NaCl}, \mathrm{CsCl}$, $\mathrm{SrCl}_{2}$, and $\left.\mathrm{EuCl}_{3}\right)$ has been added $\left(148 \mathrm{IL}^{ \pm 0.9} / 296 \mathrm{MCl}_{n}\right.$ 
solutions $\mathrm{C}, \mathrm{G}, \mathrm{K}$, and $\mathrm{L}$, respectively). Their $\mathrm{M}^{n+}$ metal content is twice the IL content, whereas the $\mathrm{Cl}^{-}$content is proportional to the $\mathrm{M}^{n+}$ charge. The evolution seen from snapshots (Figures 4 and 6) and density curves (Figure 5) fully supports increased phase separation when the $\mathrm{M}^{n+}$ charge increases, in accord with experiment. ${ }^{14,30}$ In parallel, the $\xi_{\text {demix }}$ index decreases in the order $\mathrm{CsCl}(0.61) \approx \mathrm{NaCl}(0.62)>$ $\mathrm{SrCl}_{2}(0.49)>\mathrm{EuCl}_{3}$ (0.42).

The $\mathrm{EuCl}_{3}$ solution L is clearly biphasic; at $500 \mathrm{~ns}$, all IL ions concentrate in an IL-rich slab from which $\mathrm{EuCl}_{3}$ ions are excluded, whereas all $\mathrm{Eu}^{3+}$ and $\mathrm{Cl}^{-}$ions are in an aqueous salt phase containing only ca. $3 \mathrm{BMI}^{+} \mathrm{TfO}^{-}$ion pairs. On the average, the $\mathrm{EuCl}_{3}$ density in the IL slab is zero, as is the IL density in the $\mathrm{EuCl}_{3}$ slab. In the $\mathrm{SrCl}_{2}$ solution $\mathrm{K}$, ions partition similarly as in $\mathrm{L}$, supporting complete phase separation.

This contrasts with the $\mathrm{CsCl}$ solution $\mathrm{G}$ that does not display complete phase separation, in agreement with experiment, ${ }^{14}$ but the ions still segregate into different domains. Comparing now $\mathrm{CsCl}$ to $\mathrm{NaCl}$, we observe no clear distinction between the two salts, in spite of the higher ABS-promoting effect of $\mathrm{NaCl}$ : final snapshots, density curves, and $\xi_{\text {demix }}$ values are similar.

The water content of the IL domain also decreases upon ion segregation along the $\mathrm{NaCl}, \mathrm{SrCl}_{2}$, and $\mathrm{EuCl}_{3}$ series, where the lowest $d_{\text {wat-min }}$ water densities are $\approx 0.5$ (in $\mathrm{C}$ ), 0.4 (in $\mathrm{K}$ ), and 0.2 (in L), respectively (Figure 6). A similar evolution is observed when the salt concentration increases; for instance, in the $\mathrm{NaCl}$ series, $d_{\text {wat-min }}$ drops from $\approx 0.8$ (in solution A) to 0.6 (in B), 0.5 (in C), and 0.4 (in D). Compare also solutions $\mathrm{J}$ to $\mathrm{K}$ or $\mathrm{G}$ to $\mathrm{H}$ (Figure 5). Thus, the higher the degree of ion segregation, the less humid is the IL phase, reflecting the "water dragging effect" of the salt on aggregation (see Section $3.4)$.

3.4. IL and Salt Ion Hydration and Mutual Interactions in the $\mathrm{MCl}_{n}$-Containing Solutions: Comparison with the Pure Aqueous IL or Salt Solutions. In this section, we analyze how the IL segregation induced by $\mathrm{MCl}_{n}$ salts modulates the solvation of the $\mathrm{M}^{n+}, \mathrm{Cl}^{-}, \mathrm{TfO}^{-}$, and $\mathrm{BMI}^{+}$ ions and their mutual interactions in the final $\mathrm{MCl}_{n} / \mathrm{IL}$ mixtures, as compared to the aqueous solutions of $\mathrm{MCl}_{n}$ alone (no IL) and of IL alone (solution A). For consistency, we first select solutions containing same numbers of $\mathrm{MCl}_{n}$ units (296) and of $\mathrm{IL}^{ \pm 0.9}$ ones (148), that is, solutions $\mathrm{C}, \mathrm{K}$, and $\mathrm{L}$.

The $\mathrm{M}^{n+}$ and $\mathrm{Cl}^{-}$ions being quite hydrophilic, their first hydration shell in a given mixture is very similar to the one in pure water (see RDFs in Figure S6 and Table S3 of the Supporting Information). For instance, there are $5.3 \mathrm{OH}_{2}$ around $\mathrm{Na}^{+}$and $6.8 \mathrm{H}_{2} \mathrm{O}$ around $\mathrm{Cl}^{-}$in mixture $\mathrm{C}$, versus 5.4 and 6.8, respectively, in pure water. Likewise, there are 6.9 $\mathrm{OH}_{2}$ around $\mathrm{Sr}^{2+}$ and $6.1 \mathrm{H}_{2} \mathrm{O}$ around $\mathrm{Cl}^{-}$in mixture $\mathrm{K}$, versus 7.2 and 6.3, respectively, in pure water. One also observes some $\mathrm{M}^{n+\ldots} \mathrm{Cl}^{-}$pairs, like in the mixture as in water (ca. 0.3 pairs per $\mathrm{Na}^{+}, 0.9$ per $\mathrm{Sr}^{2+}$, and 2.8 per $\mathrm{Eu}^{3+}$ ). All RDFs display a second peak, also similar in the mixture to the one in water. In the context of ABS formation, note that the $\mathrm{M}^{n+} \cdots \mathrm{M}^{n+}$ and $\mathrm{M}^{n+} \ldots \mathrm{Cl}^{-} \mathrm{RDF}$ s have higher intensities in a given mixture (red curves of Figure S6 in the Supporting Information) than in water (blue curves), reflecting the $\mathrm{MCl}_{n}$ salt segregation induced by IL ions.

The hydration of $\mathrm{TfO}^{-}$and $\mathrm{BMI}^{+}$ions and their mutual interactions are markedly modified by the added salts (see Figure 8 and Table 3). Their RDFs with water display a peak,

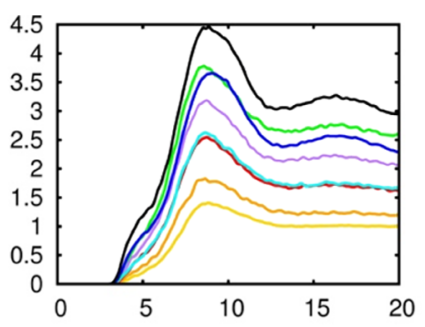

BMI ${ }^{\cdots} \mathrm{BMI}$
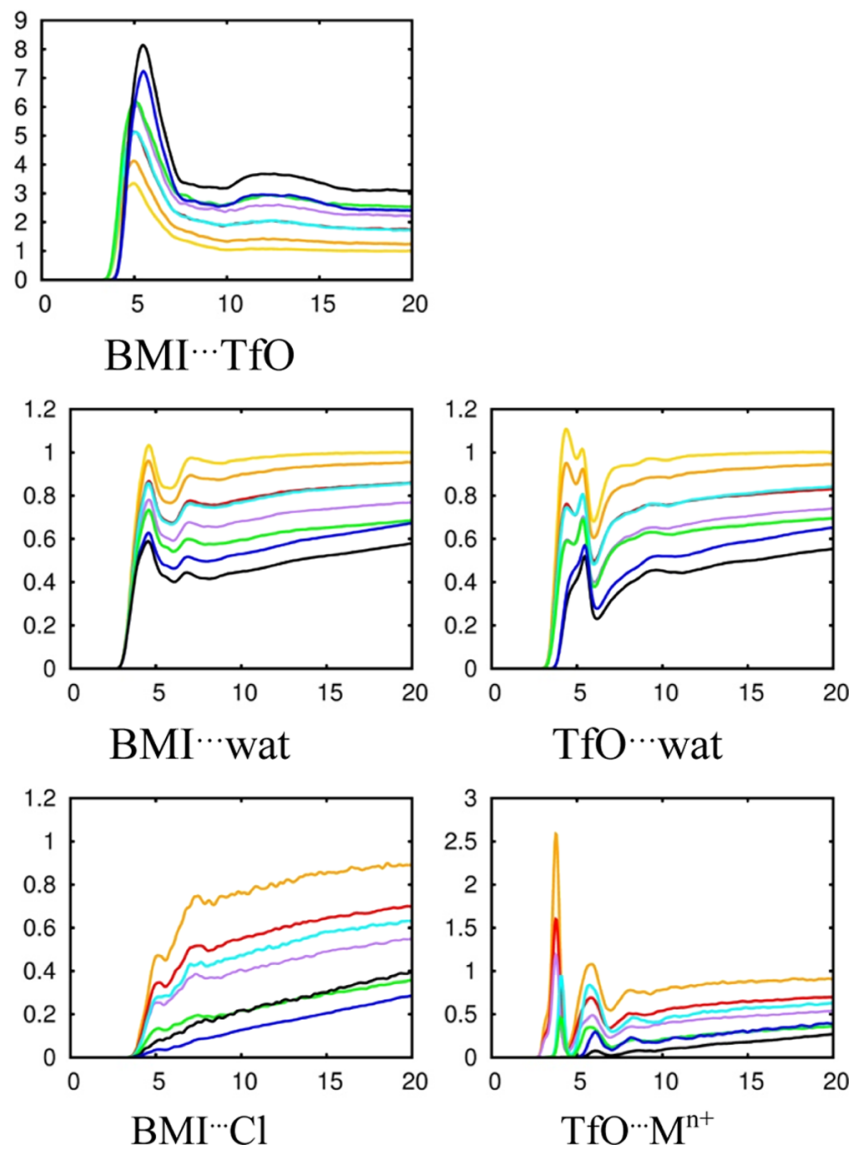

Figure 8. RDFs of $\mathrm{IL}$ ions in $148 \mathrm{IL}^{ \pm 0.9} / \mathrm{MCl}_{n}$ solutions A (no salt: yellow), B (148 NaCl: orange), C (296 NaCl: red), D (444 NaCl: purple), J (148 $\mathrm{SrCl}_{2}:$ cyan), K (296 $\mathrm{SrCl}_{2}$ : green) L (296 $\mathrm{EuCl}_{3}$ : black), and $\mathrm{P}\left(25 \mathrm{EuCl}_{3}\right.$ : blue). The corresponding integration numbers are given in Table 3.

indicating that they are coordinated to $\mathrm{H}_{2} \mathrm{O}$ molecules in their first shell, in a decreasing number, $n_{\mathrm{H}_{2} \mathrm{O}}$, along the $\mathrm{CsCl}, \mathrm{NaCl}$, $\mathrm{SrCl}_{2}$, and $\mathrm{EuCl}_{3}$ salt series. For instance, when going from the $\mathrm{NaCl}$ - to the $\mathrm{EuCl}_{3}$-containing mixture, $n_{\mathrm{H}_{2} \mathrm{O}}\left(\mathrm{BMI}^{+}\right)$drops from 14.7 to 9.7, whereas $n_{\mathrm{H}_{2} \mathrm{O}}\left(\mathrm{TfO}^{-}\right)$drops from 13.4 to 6.7 . Thus, although most $\mathrm{M}^{n+}$ and $\mathrm{Cl}^{-}$ions sit in salt-rich domains, they indirectly influence the hydration of IL ions, in keeping with the diminished water content of the IL domain. As a result, mutual interactions between IL ions (and hence segregation) are also strengthened by the added $\mathrm{MCl}_{n}$ salt: see the evolution of the $\mathrm{TfO}^{-} \ldots \mathrm{BMI}^{+}$and $\mathrm{TfO}^{-} \ldots \mathrm{TfO}^{-} \mathrm{RDF}$, where the first peaks (at $\approx 5-6 \AA$ ) increase in magnitude when $\mathrm{MCl}_{n}$ becomes more hydrophilic (see also integration numbers in Table 3).

The influence of the added salt on the "IL structure" is likewise observed in the $\mathrm{NaCl}$ series (Figure 8 and Table 3): 
Table 3. Characteristics of RDFs of IL Ions in $148 \mathrm{IL}^{ \pm 0.9} / \mathrm{MCl}_{n}$ Solutions (See Figure 8): Integration Numbers (up to Indicated Distances)

\begin{tabular}{|c|c|c|c|c|c|c|c|c|c|c|}
\hline solution & dry IL & $\begin{array}{c}\text { A } \\
0 \mathrm{NaCl}\end{array}$ & $\begin{array}{c}\mathrm{A} 2 \\
0 \mathrm{NaCl}\end{array}$ & $\begin{array}{c}\text { B } \\
148 \mathrm{NaCl}\end{array}$ & $\begin{array}{c}\mathrm{C} \\
296 \mathrm{NaCl}\end{array}$ & $\begin{array}{c}\mathrm{D} \\
444 \mathrm{NaCl}\end{array}$ & $\begin{array}{c}\mathrm{J} \\
148 \mathrm{SrCl}_{2}\end{array}$ & $\begin{array}{c}\mathrm{K} \\
296 \mathrm{SrCl}_{2}\end{array}$ & $\begin{array}{c}\mathrm{L} \\
296 \mathrm{EuCl}_{3}\end{array}$ & $\begin{array}{c}\mathrm{P} \\
25 \mathrm{EuCl}_{3}\end{array}$ \\
\hline 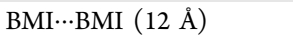 & 17.9 & 3.5 & 3.7 & 4.9 & 5.6 & 8.6 & 8.7 & 8.6 & 10.3 & 9.7 \\
\hline 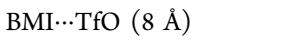 & 6.1 & 1.8 & 1.8 & 1.6 & 1.9 & 2.7 & 2.9 & 2.6 & 3.1 & 3.9 \\
\hline TfO $\cdots$ TfO ( $8 \AA)$ & 4.0 & 1.1 & 1.1 & 2.3 & 2.7 & 3.6 & 2.2 & 3.5 & 4.1 & 2.9 \\
\hline 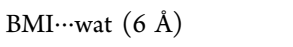 & & 17.6 & 17.3 & 15.4 & 14.7 & 12.1 & 13.8 & 11.9 & 9.7 & 10.1 \\
\hline TfO $\cdots$ wat $(6 \AA)$ & & 17.9 & 17.6 & 15.3 & 13.4 & 9.8 & 12.4 & 10.1 & 6.7 & 7.5 \\
\hline$S_{\mathrm{TfO}} \cdots$ wat $(5 \AA)$ & & 9.0 & 9.1 & 8.5 & 7.5 & 6.6 & 7.4 & 6.2 & 4.5 & 5.1 \\
\hline$S_{\text {TfO }} \cdots$ wat $(7 \AA)$ & & 30.0 & 30.6 & 27.5 & 23.1 & 19.3 & 23.1 & 18.6 & 12.4 & 14.8 \\
\hline $\mathrm{S}_{\mathrm{TfO}} \cdots \mathrm{M}^{n+}(4.5 \AA)$ & & & & 0.13 & 0.16 & 0.18 & 0.04 & 0.04 & 0.00 & 0.00 \\
\hline $\mathrm{S}_{\mathrm{TfO}} \cdots \mathrm{M}^{n+}(7 \AA)$ & & & & 0.50 & 0.65 & 0.68 & 0.29 & 0.25 & 0.03 & 0.01 \\
\hline $\mathrm{N}_{\text {butyl }}(\mathrm{BMI}) \cdots \mathrm{Cl}^{-}(5.5 \AA)$ & & & & 0.08 & 0.12 & 0.13 & 0.09 & 0.09 & 0.03 & 0.00 \\
\hline
\end{tabular}

when going from solutions $\mathrm{A}$ (without $\mathrm{NaCl}$ ) to $\mathrm{D}$, the IL ions lose ca. 5-8 $\mathrm{H}_{2} \mathrm{O}$ molecules in their first shell and display more frequent $\mathrm{TfO}^{-} \ldots \mathrm{BMI}^{+}$and $\mathrm{TfO}^{-} . . . \mathrm{TfO}^{-}$contacts, as seen from the increasing magnitude of first peak of the corresponding RDFs.

The cross-interactions between $\mathrm{M}^{n+}$ and $\mathrm{Cl}^{-}$ions and the polar moieties of the IL were analyzed more precisely in the $\mathrm{NaCl}$ series $\mathrm{B}-\mathrm{D}$ and in the $\mathrm{MCl}_{n}$ series $\mathrm{C}, \mathrm{K}$, and $\mathrm{L}$, from the $\mathrm{S}_{\mathrm{TfO}} \cdots \mathrm{M}^{n+}$ and $\mathrm{N}_{\text {butyl }}(\mathrm{BMI}) \cdots \mathrm{Cl}^{-} \mathrm{RDF}$ (a summary is given in Table 3). The $\mathrm{S}_{\mathrm{TfO}} \cdots \mathrm{M}^{n+}$ RDFs display a first peak that integrates within $4.4 \AA$ to less than 0.2 in the $\mathrm{Na}^{+}$series and to 0.04 in the $\mathrm{M}^{n+}$ series, indicating the limited occurrence of direct $\mathrm{SO}_{3}{ }^{-} \cdots \mathrm{M}^{n+}$ contacts with the divalent or trivalent ions. The second peaks, corresponding to water-mediated $\mathrm{SO}_{3}{ }^{-} \ldots$ $\left(\mathrm{H}_{2} \mathrm{O}\right) \cdots \mathrm{M}^{n+}$ contacts, increase in intensity when the $\mathrm{NaCl}$ salt gets more concentrated (ca. $0.50,0.65$, and 0.68 , respectively, within $7 \AA$ in the $\mathrm{NaCl}$ series $\mathrm{B}-\mathrm{D}$ ). In the case of $\mathrm{SrCl}_{2}$ or $\mathrm{EuCl}_{3}$ salts, the closest interactions are water-mediated and limited ( 0.25 with $\mathrm{Sr}^{2+}, 0.04$ with $\mathrm{Eu}^{3+}$ within $7 \AA$ ) because their more charged cations increasingly prefer more remote water. One observes also some $\mathrm{Cl}^{-} \ldots \mathrm{BMI}^{+}$interactions, increasing in the $\mathrm{NaCl}$ series (from ca. 0.08 to 0.13 within $5.5 \AA$ ) , but less obvious with $\mathrm{SrCl}_{2}$ or $\mathrm{EuCl}_{3}$ (0.09 and 0.03, respectively) that induce higher segregation.

Comparing now the RDFs along the whole $\mathrm{MCl}_{n}$ salt series at a fixed concentration, one observes no marked discontinuity between mono- and biphasic systems, indicating that shortrange (first shell) interactions with the ions are not sufficient to distinguish ABS from heterogeneous monophasic solutions.

3.5. Evolution of Ion Hydration and Mutual Interactions at Different Distances When "Organization" Proceeds. How the IL and salt ions, initially randomly dispersed in the mixtures, progressively segregate and how in parallel water rearranges during the dynamics around these ions have been analyzed at different distances for selected monophasic and biphasic systems. For this purpose, we followed the average number $n_{\mathrm{A}}(\mathrm{X}$; cutoff) of $\mathrm{X}$ species around $\mathrm{A}$ at different cutoff distances, 5, 10, and $20 \AA$. The corresponding curves are given in Figures 9, S21, and S22, respectively, of the Supporting Information.

Regarding the hydration of $\mathrm{MCl}_{n}$ salts, the $n_{\mathrm{H}_{2} \mathrm{O}}\left(\mathrm{M}^{n+} ; 5\right)$ or $n_{\mathrm{H}_{2} \mathrm{O}}\left(\mathrm{Cl}^{-} ; 5\right)$ curves are rather flat, indicating that the hydrophilic $\mathrm{M}^{n+}$ and $\mathrm{Cl}^{-}$ions rapidly satisfy their first coordination requirements in the different solutions. This contrasts with the $n_{\mathrm{H}_{2} \mathrm{O}}\left(\mathrm{BMI}^{+} ; 5\right)$ or $n_{\mathrm{H}_{2} \mathrm{O}}\left(\mathrm{TfO}^{-} ; 5\right)$ curves that decay rapidly (indicating rapid loss of water) and become flat after ca. 10 ns. Hydration changes at longer distances (10 or 20 $\AA$ ) are slower and more spectacular, in keeping with the water migration from (forming) IL domains toward (forming) salt domains. The water transfer increases when $\mathrm{MCl}_{n}$ becomes more salting-out. For instance, during the first $100 \mathrm{~ns}$ of dynamics, $n_{\mathrm{H}_{2} \mathrm{O}}\left(\mathrm{M}^{n+} ; 20\right)$ increases in the order $\mathrm{Cs}^{+} \approx \mathrm{Na}^{+}<$ $\mathrm{Sr}^{2+}<\mathrm{Eu}^{3+}$, by $\approx 100 \mathrm{H}_{2} \mathrm{O}$ in the $\mathrm{Eu}^{3+}$ case. In parallel, $n_{\mathrm{H}_{2} \mathrm{O}}\left(\mathrm{BMI}^{+} ; 20\right)$ and $n_{\mathrm{H}_{2} \mathrm{O}}\left(\mathrm{TfO}^{-} ; 20\right)$ drops in the same $\mathrm{M}^{n+}$ order, by $\approx 300 \mathrm{H}_{2} \mathrm{O}$ in the case of $\mathrm{Eu}^{3+}$. Ion segregation and phase separation, concomitant with water transfer, are reflected by the populations of BMI $\cdots \mathrm{BMI}, \mathrm{BMI} \cdots \mathrm{TfO}$, and TfO $\cdots \mathrm{TfO}$ "pairs" that increase (at the three distances) when $\mathrm{MCl}_{n}$ becomes more salting-out (Figures 9, S21, and S22 of the Supporting Information), with marked changes at long distances. It is thus crucial to look beyond the first coordination shells of the different partners.

\section{DISCUSSION}

These MD "demixing" simulations of aqueous solutions of $\mathrm{MCl}_{n}$ and IL, their components initially placed in random positions, have enabled exploration of as to what extent the solutions become mono- or biphasic at the nanoscopic level and thereby provide microscopic insights into ion segregation and ABS formation. To achieve "apples with apples" comparisons, the MD experiments were conducted in a systematic manner, comparing different salt/IL concentrations and $\mathrm{MCl}_{n}$ metallic salts along the Hofmeister series. They reveal in all cases marked heterogeneities, with segregation of the IL ions into a water domain from which the $\mathrm{M}^{n+}$ and $\mathrm{Cl}^{-}$ ions tend to be excluded and the converse. Ion segregation (and in some cases, full phase separation) is found to increase (i) when the added $\mathrm{M}^{n+}$ ions are higher charged (and hence more hydrophilic) and (ii) more concentrated and (iii) with the IL content. This is consistent with experimental observations. ${ }^{14}$ In the following, we first address computational and related physical issues and compare the calculated to the experimental phase behavior of all systems, comparing the $\mathrm{IL}^{ \pm 1}$ to $\mathrm{IL}^{ \pm 0.9}$ models. To discern the driving forces for $\mathrm{ABS}$ formation, we then analyze changes in ion hydration, ion-ion interactions, and the water migration, also comparing these concentrated IL mixtures to IL diluted ones. This is followed by a discussion of some related energy features. Ion organization and hydration patterns in the IL phase of ABSs are then discussed, drawing analogies with IL ions at aqueous interfaces. Finally, the main characteristics of liquid-liquid 


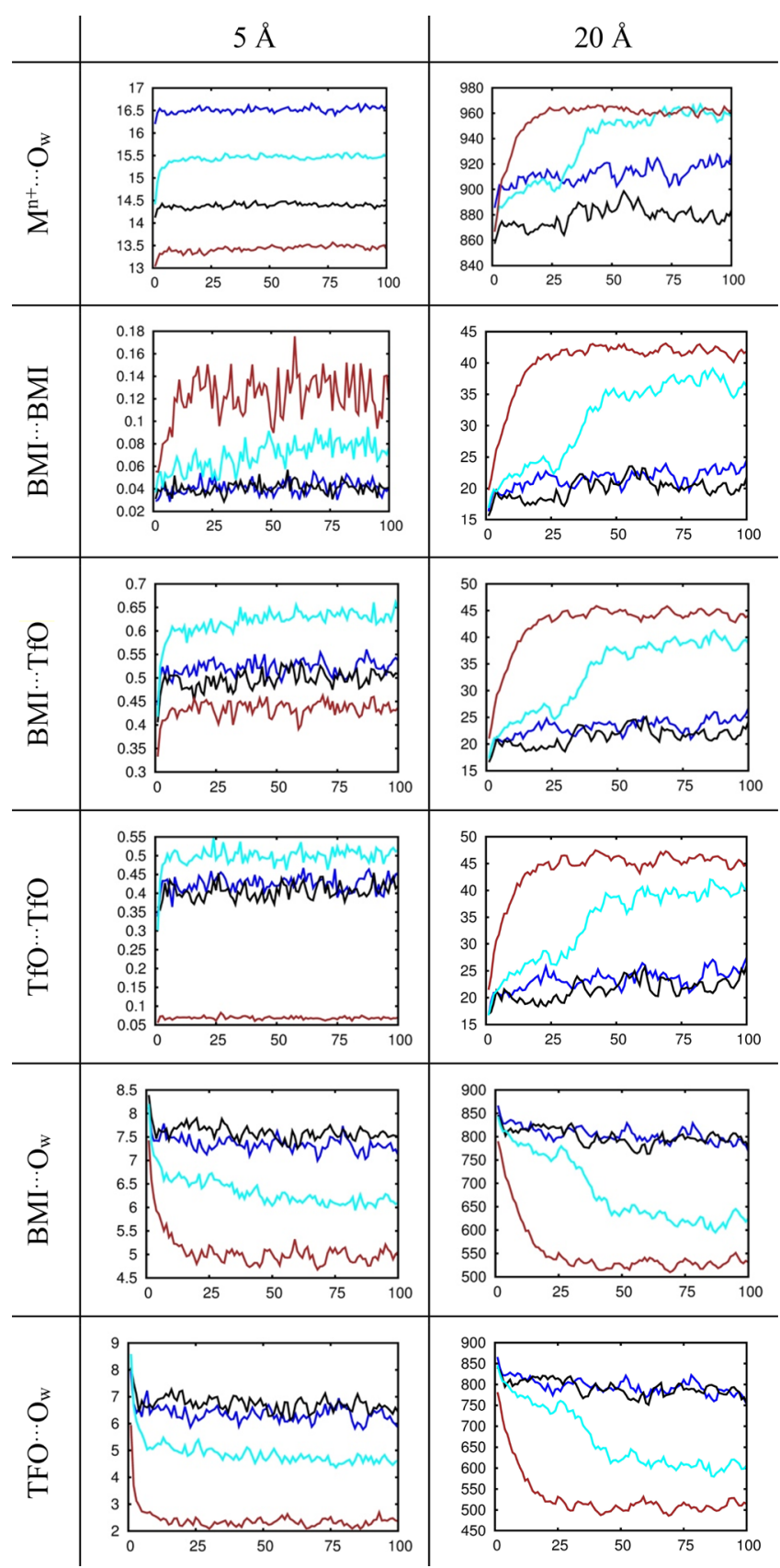

Figure 9. $148 \mathrm{IL}^{ \pm 0.9} / 296 \mathrm{MCl}_{n}$ solutions: integration number of RDFs up to 5 and $20 \AA$ as a function of time (in ns). Color codes: $\mathrm{NaCl}$ blue, $\mathrm{CsCl}$, black, $\mathrm{SrCl}_{2}$ cyan, and $\mathrm{EuCl}_{3}$ brown. An extended version is given in Figure S22.

interfaces of ABSs are compared to those of "oil"/water interfaces.

4.1. Computational and Related Physical Issues. Owing the simplicity of the force field used here, quantitative agreement with thermodynamic partition data is not anticipated. As will be seen below, the charges borne by IL ions critically influence the extent of IL segregation, and the tested $\mathrm{IL}^{ \pm 0.9}$ and $\mathrm{IL}^{ \pm 1}$ models likely bracket the best compromise. Interactions with water and thereby the segregation behavior, are also influenced by the water and ion models ${ }^{54}$ (see for instance refs ${ }^{55-58}$ for IL ions and ref 59 for salt ions) and by polarization effects. ${ }^{60,61}$
Simulation times also matter. Note that those used here (500-1000 ns) are longer than those used to separate classical water/"oil" random mixtures $(<0.2 \mathrm{~ns}$ when "oil" is an organic molecule or $\mathrm{SC}-\mathrm{CO}_{2}{ }^{53,62}$ or $20-40 \mathrm{~ns}$ when the "oil" is a hydrophobic $\left.\mathrm{IL}^{46}\right)$. The purely aqueous mixtures separate more slowly, indicating that the underlying driving forces are weaker, thereby needing to sample more configurations. Shortrange reorganization of the random mixtures generally occurs during the first $\approx 10-20$ ns. After that time period, the demixing index $\xi_{\text {demix }}$ (Figure 3 ) and the different energy components (see below) stay fairly constant, indicating that segregation does not significantly change at the nanometer scale. Looking at specific cases illustrates typical steps of ABS formation. For instance, for the $\mathrm{EuCl}_{3}$ solution $\mathrm{L}$ (see S8 of the Supporting Information), the ions form loose aggregates during the first ca. 5-10 ns and then condense (between 10 and $25 \mathrm{~ns}$ ) into an IL slab and a small IL droplet, $\approx 10 \mathrm{~nm}$ apart. At $\approx 225 \mathrm{~ns}$, these collapse into a single IL phase that remains stable until the end. In the case of the $\mathrm{NaCl}$ solution $\mathrm{D}$, the two distinct phases formed earlier (at $\approx 160 \mathrm{~ns}$ ), indicating that the different landscapes obtained at $500 \mathrm{~ns}$ are overall meaningful. In the case of the $\mathrm{SrCl}_{2}$ solution $\mathrm{K}$, cumulated trajectories of individual species during $100 \mathrm{~ns}$ (Figure S7) also show that the sampling is sufficient to study ABSs.

Another issue concerns the size of solvent heterogeneities: are they representative of the macroscopic ones or induced by the box size and content? In particular, is the number of IL ion pairs (148) in the "standard" simulations not too small to finally depict a bulk phase? This is clearly not the case for the $\mathrm{NaCl}, \mathrm{SrCl}_{2}$, and $\mathrm{EuCl}_{3}$ solutions (D, K, and L, respectively) that form two phases in the "standard box". For the $\mathrm{NaCl}$ solution $\mathrm{D}$, however, we decided to test a "bigger box" (solution D2) of size and content scaled up by 4.0. The snapshots in Figure 10 and density curves in Figure 6 confirm

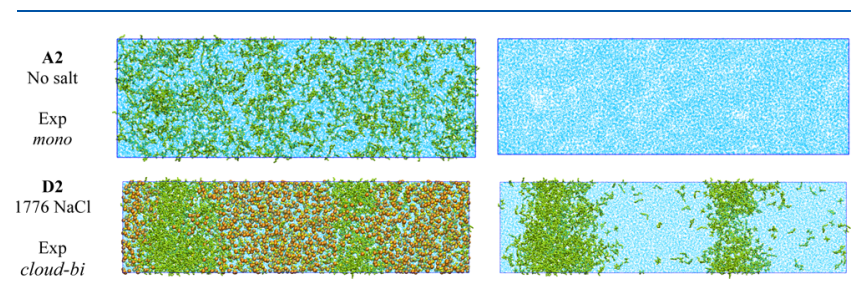

Figure 10. "Big box" simulations on $\mathrm{IL}^{ \pm 0.9}$ solutions with no salt (A2) and with $\mathrm{NaCl}$ (D2) after $200 \mathrm{~ns}$ (A2) and $500 \mathrm{~ns}$ (D2).

the separation of $\mathrm{IL}$ and $\mathrm{NaCl}$ ions into distinct domains, forming now two slabs per ion type. These differ in size and composition, however; the first one is wider and contains more IL (and hence less water) than the second one, suggesting that the system is metastable. Because these two slabs are $\approx 10 \mathrm{~nm}$ apart, there is no driving force inducing their collapse during $500 \mathrm{~ns}$ of dynamics.

The shape of ionic phases can also be influenced by the shape of the box, when simulated with $3 \mathrm{D}$ periodic conditions: rectangular elongated boxes favor slabs, whereas cubic boxes rather favor cylindrical or "spherical" IL arrangements (see e.g., the case of the $\mathrm{EuCl}_{3}$ solution L; Figure S9 of the Supporting Information). Whether and how these domains collapse after longer simulations remains to be investigated with bigger systems. Beyond being a computational issue, this may become of importance for experiments carried out in confined conditions. Furthermore, as experimentally observed for the 
big "spherical" dicarbollide anions that also form nanoaggregates in water, ${ }^{63}$ the structure of the solutions (mainly the monophasic ones) may evolve with time and aging. ${ }^{64}$

4.2. Monophasic/Biphasic State of IL/MCl $n$ Mixtures, Simulated with $\mathrm{IL}^{ \pm 1}$ Versus $\mathrm{IL}^{ \pm 0.9}$ Charge Models: Comparison with Experiment. For the $\mathrm{MCl}_{n}$ containing mixtures, increasing the IL ion "polarity" (from the $\mathrm{IL}^{ \pm 0.9}$ to the $\mathrm{IL}^{ \pm 1}$ model) diminishes segregation, as indicated by the $\xi_{\text {demix }}$ index that decreases by $\approx 0.1$ units, on the average (see evolutions with time in Figure $\mathrm{S} 10$ of the Supporting Information and average values in Table 2). See also snapshots (Figures S11-S14 of the Supporting Information) and density curves (Figures S15-S17 of the Supporting Information) obtained with the $\mathrm{IL}^{ \pm 1}$ charges. With the latter, segregation also increases with the salt content (compare $\xi_{\text {demix }}$ for $\mathrm{NaCl}$ solutions $\mathrm{B}$ to $\mathrm{D}, \mathrm{CsCl}$ solutions $\mathrm{G}$ to $\mathrm{H}$, and $\mathrm{SrCl}_{2}$ solutions $\mathrm{J}$ to $\mathrm{K}$ ) and with the $\mathrm{M}^{n+}$ charge (compare $\xi_{\text {demix }}$ for solutions $\mathrm{C}$, $\mathrm{K}$, and $\mathrm{L}$ ). The effect of the IL content is less clear, however; $\xi_{\text {demix }}$ is similar for the $\mathrm{C}$ and $\mathrm{E} \mathrm{NaCl}$ solutions, as for the $\mathrm{D}$ to $\mathrm{F}$ ones that do not display ion partitioning with that model (Figure S11 of the Supporting Information).

We now aim at comparing the simulated phase behavior to that experimentally observed (Figure 1). Biphasic and monophasic systems at points near the coexistence curve (and hence the cloud point) are noted "cloud-bi" or "cloudmono", respectively, on the different snapshots and density curves. On the simulation side, the distinction is rarely clearcut, in particular when broad density peaks (also corresponding to some salt/IL mixing), instead of plateaus, are observed. Furthermore, the IL or salt domains are labile and fluctuate with time, as seen from the evolution of density profiles with averaging time (e.g., 50, instead of $5 \mathrm{~ns}$ ). Notwithstanding these issues, tentative assignments (Table S4 of the Supporting Information) yield the following trends. With the $\mathrm{IL}^{ \pm 1}$ charges, most monophasic states (e.g., $\mathrm{NaCl}$ solutions $\mathrm{B}$ and $\mathrm{C}, \mathrm{CsCl}$ solutions $\mathrm{G}$ and $\mathrm{H}$ ) are correctly predicted to be so: the density profiles are more or less flat, with significant $\mathrm{IL} / \mathrm{salt}$ mixing. Most biphasic solutions (e.g., $\mathrm{NaCl}$ solution $\mathrm{F}, \mathrm{SrCl}_{2}$ solution $\mathrm{K}$ ), however, are predicted instead to be monophasic, though with significant IL/salt mixing. Biphasic solutions sitting near the coexistence curve (e.g. $\mathrm{NaCl}$ solutions $\mathrm{D}$ and $\mathrm{D} 2, \mathrm{CsCl}$ solution I) also look monophasic. The only clear-cut "success" of the $\mathrm{IL}^{ \pm 1}$ model concerns the $\mathrm{EuCl}_{3}$ solution $\mathrm{L}$ that remains biphasic. On the other hand, with the $\mathrm{IL}^{ \pm 0.9}$ model, monophasic solutions (e.g., $\mathrm{NaCl}$ solution $\mathrm{C}, \mathrm{CsCl}$ solution $\mathrm{H}$ ), some of them sitting near the coexistence curve (e.g. $\mathrm{NaCl}$ solution E) are instead found to be biphasic, which suggests somewhat exaggerated segregation and phase separation. Thus, to summarize, the $\mathrm{IL}^{ \pm 1}$ model correctly predicts monophasic states but underestimates segregation and phase separation, whereas the $\mathrm{IL}^{ \pm 0.9}$ model somewhat magnifies segregation. More fundamentally, the comparison of the $\mathrm{IL}^{ \pm 1}$ to the $\mathrm{IL}^{ \pm 0.9}$ results illustrates the subtle influence of IL ion "polarity" in the formation of ABSs. See, for example, the case of the $\mathrm{NaCl}$ solution $\mathrm{E}$ that becomes biphasic with the $\mathrm{IL}^{ \pm 0.9}$ charges and monophasic with the $\mathrm{IL}^{ \pm 1}$ ones.

For the $\mathrm{EuCl}_{3}$ solution $\mathrm{L}$, there are no experimental data. However, the simulations make clear that this salt has the strongest $\mathrm{ABS}$ inducing effect. Even in the more dilute $\mathrm{EuCl}_{3}$ solutions $\mathrm{M}, \mathrm{N}, \mathrm{O}$, and $\mathrm{P}$, one observes distinct IL and salt domains, that is, phase separation, with either $\mathrm{IL}^{ \pm 1}$ or $\mathrm{IL}^{ \pm 0.9}$ models (see Figures S18 and S19 of the Supporting Information).
4.3. Water Reorganization and Ion Segregation: Water Migration from the Best "Water-Donating" Ion Pair to the Best "Water-Accepting" Ion Pair. Ion-specific effects on $\mathrm{ABS}$ formation phenomenologically follow the Hofmeister series established for the precipitation/solubilization of proteins ${ }^{15-17,65}$ and the order of ion effects on aqueous solubilities of hydrophilic and hydrophobic IL ions, ${ }^{14,26}$ biomolecules, ${ }^{11}$ or sugars, ${ }^{66}$ for instance. They result from collective phenomena and from the interplay between all ion... water, ion $\cdots$ ion, and solvent $\cdots$ solvent interactions at a given concentration. The formation of ABSs with hydrophilic ILs induced by inorganic salts increases with the salting-out properties of the salt, that is, with its concentration and hydrophilicity. ${ }^{7,14,26}$ It results from the competition between the salt ions and IL ions to capture water, which is won by the most hydrophilic ones. ${ }^{3,30}$ Cross salt/IL interactions may also come into play. Studying the effect of organic and inorganic salts (including alkali and alkaline earth metal chlorides) on the solubility of the (weakly soluble) $[\mathrm{BMI}]\left[\mathrm{TF}_{2} \mathrm{~N}\right] \mathrm{IL}$, Freire et al. mentioned "specific ion effects that result from the direct or indirect (water-mediated) interactions between the salt ions and the solute and not from a rearrangement of the water molecules caused by the ions". They also assigned the resulting favorable effect to the tendency to form "hydration complexes" which cause the "dehydration of the solute". In another study with the water-soluble [BMI][TfO] IL, Kurnia et al. reported negative NMR chemical shifts on $\mathrm{H}_{\mathrm{BMI}}$ and $\mathrm{F}_{\mathrm{TfO}}$ IL atoms upon addition of $\mathrm{NaCl}, \mathrm{MgCl}_{2}$, and $\mathrm{AlCl}_{3}$ salts, interpreted in terms of "unfavorable interactions between the IL and salt leading to a salting-out phenomenon". ${ }^{30}$ Our simulations consider higher IL concentrations, high enough to form ABSs $\left(\approx 1-2\right.$, instead of $0.01 \mathrm{~mol} \mathrm{~kg}^{-1}$ in their studies $)$ and cannot be directly compared because at high IL concentration, the IL and salt ions tend to be located in different domains of the solutions.

To analyze what happens prior to segregation (at low IL concentration), we simulated $2 \mathrm{M}$ salt/0.02 $\mathrm{M}$ IL aqueous solutions with $\mathrm{NaCl}, \mathrm{SrCl}_{2}$, and $\mathrm{EuCl}_{3}$ salts and analyzed the corresponding RDFs (their main characteristics are given in Table S5 of the Supporting Information). There are, as expected, no contacts between the dilute IL ions. Their first hydration shells are similar in the $\mathrm{NaCl}, \mathrm{SrCl}_{2}$, and $\mathrm{EuCl}_{3}$ solutions (ca. $21 \mathrm{H}_{2} \mathrm{O}$ within $6 \AA$ ) and similar to that in the absence of salt, in keeping with the lack of significant IL/salt direct contacts. The closest contacts are water-mediated: the $\mathrm{S}_{\mathrm{TfO}} \cdots \mathrm{M}^{n+}$ and $\mathrm{N}_{\text {butyl }} \cdots \mathrm{Cl}^{-} \mathrm{RDFs}$ integrate to ca. 1.5 (at $7 \AA$ ) and to ca. $0.3-0.6$ (at $5.5 \AA$ ), respectively, for the three salts. Looking at longer distances, one finds a similar number of $\mathrm{S}_{\mathrm{TfO}} \cdots \mathrm{M}^{n+}$ pairs for the three salts (ca. $4.5 \mathrm{M}^{n+}$ within $10 \AA$ from $\mathrm{TfO}^{-}$). The main perturbations of the IL ion environment thus occur mainly via water (e.g., through reorientation and/or polarization of their dipoles and modulation of their $\mathrm{H}$ bonding interactions), in an increasing manner when the $\mathrm{M}^{n+}$ charge (and, accordingly, the $\mathrm{Cl}^{-}$concentration and number of $\mathrm{Cl}^{-} . . \mathrm{BMI}^{+}$contacts) increases. This is overall consistent with the reported shifts in the NMR spectra and with their interpretation. ${ }^{30}$ Such short-range interactions are not sufficient, however, to induce ion segregation (and finally ABS formation). When the IL concentration is increased from 0.02 to $2 \mathrm{M}$, the IL ions lose much first shell water (ca. 7, 10, and $11 \mathrm{H}_{2} \mathrm{O}$ within $6 \AA$ from $\mathrm{BMI}^{+}, 12,13$, and $18 \mathrm{H}_{2} \mathrm{O}$ around $\mathrm{TfO}^{-}$, respectively, in the $\mathrm{NaCl}, \mathrm{SrCl}_{2}$, and $\mathrm{EuCl}_{3}$ 
mixtures) in keeping with the mutual attractions between IL ions and their segregation.

Overall, the structure of the studied IL/salt mixtures can be represented in terms of synergistic water-donor/water-acceptor interactions between the different ion pairs present in the solution. Here, $\mathrm{BMI}^{+}$and $\mathrm{TfO}^{-}$IL behave as water donors (from their hydrophobic butyl and $\mathrm{CF}_{3}$ moieties, respectively), whereas the more hydrophilic $\mathrm{M}^{n+}$ and $\mathrm{Cl}^{-}$ions attract water, in the first shells and much beyond, when the ionic charge increases. Finally, the salt phase contains more water than does the IL phase. Note that ions segregate into distinct IL and salt domains whatever their origin. For instance, the $\mathrm{NaCl}$ solution $\mathrm{E}$ that contains the same number (296) of $\mathrm{Na}^{+} \mathrm{Cl}^{-}$and $\mathrm{BMI}^{+} \mathrm{TfO}^{-}$ions can alternatively be viewed as a mixture of the $\mathrm{NaTfO}$ salt with the BMICl IL, equivalent to "counterion exchange" in water: with both $\mathrm{IL}^{ \pm 0.9}$ and $\mathrm{IL}^{ \pm 1}$ models, ions are found to segregate into $\mathrm{BMI}^{+} \mathrm{TfO}^{-}$domains and into $\mathrm{Na}^{+} \mathrm{Cl}^{-}$ ones. Interestingly, in the IL domain of solution $\mathrm{E}$, the association of $\mathrm{BMI}^{+}$and $\mathrm{TfO}^{-}$ions is reminiscent of $\mathrm{BMI}^{+} \mathrm{ClO}_{4}^{-}$contacts observed in $[\mathrm{BMI}]\left[\mathrm{Tf}_{2} \mathrm{~N}\right]+\mathrm{NaClO}_{4}$ aqueous mixtures, that is, of anion exchange between the IL and salt. ${ }^{27}$ More generally, instead of focusing on a single ion type, it is worth considering all ion pairs (taking into account the precise speciation of all $\mathrm{M}_{x} \mathrm{X}_{y}$ salts in the case of multicharged ions). ${ }^{27,30}$

4.4. Evolution of Energy Components When Ion Segregation and Water Transfer Proceed. To follow the energy impact of ion and solvent reorganization occurring along the dynamics, we cut the systems into three overall neutral groups (IL ions, $\mathrm{MCl}_{n}$ ions, and water) and followed their interactions (see curves in Figure 11 and in Figures S23S25 of the Supporting Information). Regarding interaction energies with water, the salt/water one is fairly constant along the dynamics for the $\mathrm{NaCl}$ and $\mathrm{CsCl}$ solutions (that remain monophasic) but becomes much more attractive at the beginning of the dynamics for $\mathrm{SrCl}_{2}$ and $\mathrm{EuCl}_{3}$ solutions (that become biphasic). In parallel, the IL/water interaction energies, much smaller in magnitude than the salt/water ones, remain stable with $\mathrm{NaCl}$ and $\mathrm{CsCl}$, but get destabilized with $\mathrm{SrCl}_{2}$ and $\mathrm{EuCl}_{3}$, reflecting water migration from the ions of IL to those of $\mathrm{MCl}_{n}$. The IL "self-energy" also contributes to the stabilization of ABSs; it is fairly constant along the dynamics in the $\mathrm{NaCl}$ and $\mathrm{CsCl}$ solutions but becomes more attractive with $\mathrm{SrCl}_{2}$ or $\mathrm{EuCl}_{3}$ because of the enhanced $\mathrm{BMI}^{+} / \mathrm{TfO}^{-}$ attractions when the IL ions segregate.

On the thermodynamic side, the stabilization of a system corresponds to a decrease in its Gibbs free energy $\Delta G$ (in standard conditions), a feature not amenable to simulations. Insights into the evolution of its $\Delta H$ component can however be obtained by looking at the total potential energy $E_{\text {pot }}$ (Figure 11 and in Figures S23-S25 of the Supporting Information). In the $\mathrm{NaCl}$ series $\mathrm{B}$ to $\mathrm{D}, E_{\text {pot }}$ stays fairly constant throughout the dynamics, even for the most concentrated solution (D) that becomes biphasic. In the $\mathrm{MCl}_{n}$ series, $E_{\text {pot }}$ first diminishes during $\approx 10$ ns with $\mathrm{SrCl}_{2}$ and $\mathrm{EuCl}_{3}$ salts and then remains fairly constant. Note that the demixing index $\xi_{\text {demix }}$ follows a similar evolution, indicating that during that time period, the initially random solute/ solvent mixtures have become more or less homogeneous at the nanometer scale but not yet separated into two phases (for the biphasic ones). Later on, there is thus no dominant enthalpic driving force for further phase separation, which is

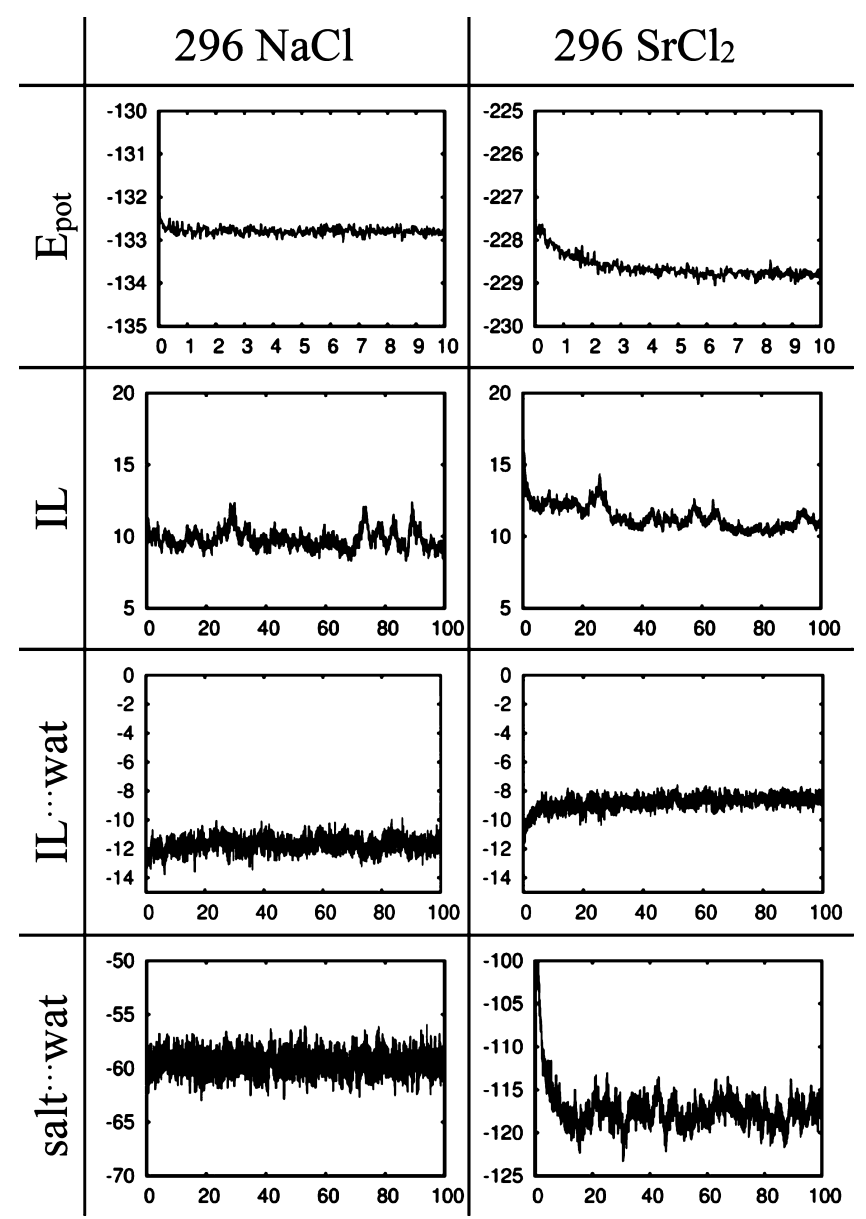

Figure 11. $148 \mathrm{IL}^{ \pm 0.9} / 296 \mathrm{MCl}_{n}$ solutions $\mathrm{C}$ and $\mathrm{K}$. Energy component analysis (in $10^{3} \mathrm{kcal} \mathrm{mol}^{-1}$ ) as a function of time. Total potential energy $E_{\text {pot }}$ during the first 10 ns. Internal IL energy and IL $\cdots$ wat and salt $\cdots$ wat interactions during the first 100 ns. An extended version is given in Figures S23-S25.

consistent with entropy-driven segregation and separation processes.

The origin of any entropic gain is unclear. Experimentally, hydration of metallic salts is an exergonic process (negative $\Delta G)$, dominated by high negative $\Delta H$ enthalpies, somewhat reduced by unfavorable $\Delta S$ entropies. ${ }^{67}$ Enriching the water environment of the salt ions upon ABS formation should thus not be a source of entropic gain. On the other hand, water is also highly structured around hydrophobic species ${ }^{68}$ and displays (weak) attractions with them, overcompensated by an unfavorable entropic cost. ${ }^{69}$ As a result, hydrophobic species tend to "expel" water from their surface and to aggregate with each other, contributing to a favorable entropic gain. The latter likely operates already in IL solution A (without $\mathrm{MCl}_{n}$ salt) where significant hydrophobic contacts $\left(\mathrm{TfO}^{-} \ldots \mathrm{TfO}^{-}, \mathrm{BMI}^{+} \ldots\right.$ $\mathrm{TfO}^{-}$) between IL ions are observed. They might explain the ability of this IL to be salted-out, even by weakly salting-out species like $\mathrm{NaCl}$, carbohydrates, ${ }^{66}$ or aminoacids. ${ }^{70}$ On the other hand, like ILs used for ABSs, it does not precipitate in concentrated conditions.

4.5. IL Phase of ABSs: Ion Hydration and Organization into "Dry"/“Humid" Domains. We have seen that the IL-rich phase of $\mathrm{ABS}$ s is mainly aqueous: even in the most dramatic cases $\left(\mathrm{NaCl}\right.$ solution $\mathrm{D}, \mathrm{SrCl}_{2}$ solution $\mathrm{K}$, and $\mathrm{EuCl}_{3}$ solution $\mathrm{L}$ ), water is in excess over IL ions (more than $\approx 800$ 
$\mathrm{H}_{2} \mathrm{O}$ molecules for at most $148 \mathrm{BMI}^{+} \mathrm{TfO}^{-}$ions). It is thus interesting to look at the state of water in the IL phase, focusing on solution L. Typical snapshots (Figure 12) make
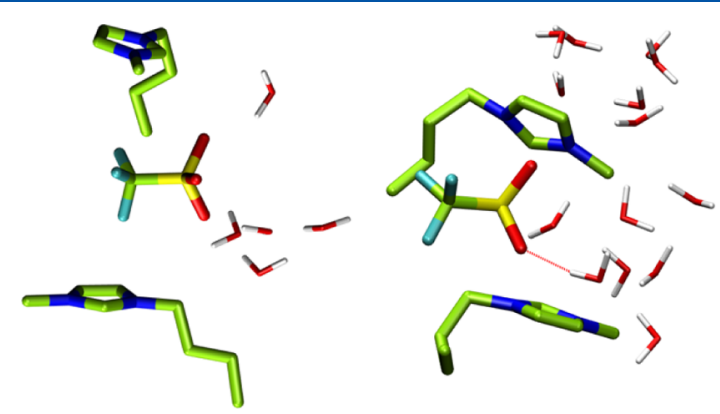

Figure 12. Typical solvated $\mathrm{BMI}^{+} \mathrm{TfO}^{-}$ion arrangements in the IL phase of the biphasic $\mathrm{EuCl}_{3}$ solution $\mathrm{L}$ (left) and at the vacuum/ aqueous-IL interface (right).

clear that water is mainly connected to the $\mathrm{SO}_{3}{ }^{-}$moiety of $\mathrm{TfO}^{-}$, via three to four strong hydrogen bonds, on the average. Conversely, there are nearly "dry" IL regions where $\mathrm{CF}_{3}$ (TfO) and methyl(BMI) or butyl(BMI) hydrophobic moieties segregate, whereas the polar interactions between $\mathrm{SO}_{3}(\mathrm{TfO})^{-}$ and ring(imidazolium $)^{+}$are most often mediated by water. Hydration of the "IL phase" of these ABSs is thus reminiscent of the one observed in hydrophobic but hygroscopic ILs. ${ }^{46,71,72}$ In particular, the IL anion is better hydrated than the cation because of H-bonding interactions. ${ }^{73}$ In the IL phase of ABSs, solvating water around polar groups tends to form filaments (in the $\mathrm{SrCl}_{2}$ solution $\mathrm{K}$ ) or aggregated fingers (in the $\mathrm{EuCl}_{3}$ solution L). The remarkable feature of ABSs is the fact that dehydration of the hydrophobic moieties is simply induced by the remote added salt, at a sufficient concentration. When the added $\mathrm{MCl}_{n}$ salt becomes less salting-out (less hydrophilic and/or less concentrated), the water content of the IL phase increases and that phase breaks up into smaller domains, droplets, or aggregates. As mentioned above, dehydration of hydrophobic moieties of the IL is entropically favored, ${ }^{11,69}$ indirectly contributing to the salting-out effect.

In the IL phase of the $\mathrm{L}$ solution, IL ions display some "organization", induced by water. We simulated the pure dry $[\mathrm{BMI}][\mathrm{TfO}] \mathrm{IL}$ for comparison (see Figure S2 of the Supporting Information). In the latter, the apolar groups also aggregate with each other, as do the polar ones. For instance, each $\mathrm{SO}_{3}(\mathrm{TfO})^{-}$is surrounded by a "cage" of 3-4 ring-

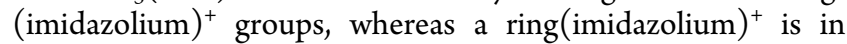
contact with 2-3 $\mathrm{SO}_{3}(\mathrm{TfO})^{-}$groups. Neither the $\mathrm{TfO}^{-}$anion nor the $\mathrm{BMI}^{+}$cation are amphiphilic enough, however, to induce longer range ordering. ${ }^{72,74,75}$ In the presence of water, these polar interactions are disrupted, whereas the apolar ones are strengthened.

4.6. Analogies between IL Patterns in ABSs and at an Aqueous Interface. The analogy between IL ion hydration patterns in $\mathrm{ABSs}$ and at aqueous interfaces is striking. First, note that both IL ions prefer the water surface over bulk water. $^{76}$ This feature is illustrated by a MD experiment we performed on the aqueous solution of $\mathrm{BMI}^{+} \mathrm{TfO}^{-}$ions at the air interface: density profiles and snapshots (Figures 13 and S27 of the Supporting Information) show that IL ions are "attracted" by the interface (more with the $\mathrm{IL}^{ \pm 0.9}$ charges than with the $\mathrm{IL}^{ \pm 1}$ ones) where they adopt amphiphilic orientations: the hydrophobic Butyl(BMI) and $\mathrm{CF}_{3}(\mathrm{TfO})$ moieties are "dry"
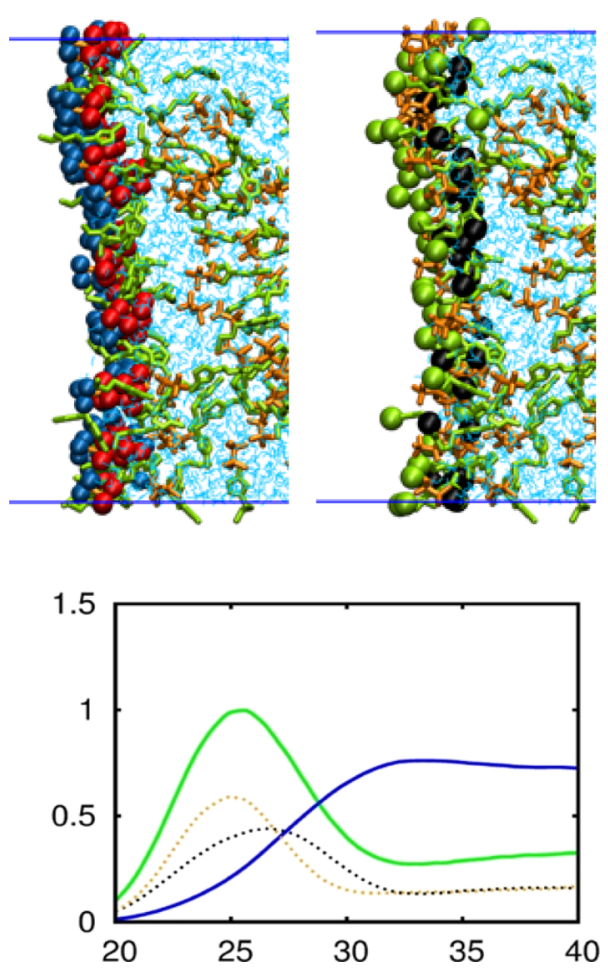

Figure 13. Vacuum/aqueous-IL interface with $296[\mathrm{BMI}][\mathrm{TfO}]^{ \pm 0.9}$. Line 1: Snapshots highlighting interfacial $\mathrm{TfO}^{-}$(left) and $\mathrm{BMI}^{+}$ions (right): $\mathrm{CF}_{3}$ in blue, $\mathrm{SO}_{3}^{-}$in red, butyl chain in green, and imidazolium ring in black. Line 2: IL and water densities, between 20 and $40 \AA$ of the $z$-axis (in $\AA$ ), averaged over 50 ns. Color codes: water blue; IL green; $\mathrm{BMI}^{+}$dotted black; and $\mathrm{TfO}^{-}$dotted orange. An extended version is given in Figure S27.

and point toward air, whereas the polar (ring)imidazolium ${ }^{+}$ and $\mathrm{SO}_{3}(\mathrm{TfO})^{-}$ones prefer water. In particular, $\mathrm{SO}_{3}{ }^{-}$is hydrated by 3-4 $\mathrm{H}_{2} \mathrm{O}$ molecules, connected to bulk water, as in $\mathrm{ABSs}$.

Calling attention to interfacial properties helps to understand why trends in ABSs formation from $\mathrm{IL} /$ salt mixtures follow the surface activity of ions and their Hofmeister series classification. $^{16,26,65}$ The studied IL ions behave as small amphiphiles, as do components of polymers like PEGs, dextrans, or water-soluble macromolecules that also form ABSs. Even "big spherical ions", some of them being components of ILs (polyoxometallate, ${ }^{77,78}$ dicarbollide, ${ }^{63,79}$ $\mathrm{ClO}_{4}^{-}$anions, ${ }^{80}$ or $\mathrm{NR}_{4}^{+}$quaternary ammonium cations) display hydrophobic features and surface activity. They also tend to aggregate in water and thus to form ABSs. In contrast, the salting-out $\mathrm{M}^{n+} \mathrm{Cl}^{-}$ions that increase the surface tension of water are instead "repelled" by the interface and prefer a bulk water environment.

4.7. Liquid-Liquid "Interface" of IL/Salt ABSs. Generally, liquid-liquid interfaces are defined with respect to the adjacent solvents (e.g., water and a hydrophobic IL)..$^{35,81-85}$ In the case of the studied ABSs, the average $z$ position of the interface $\langle z\rangle_{\text {ITF }}$ might be defined by the $z$-plane where the water density $d_{\text {wat-ITF }}$ is the mean of densities in the IL slab and in the salt slab: $d_{\text {wat-ITF }}=1 / 2\left(d_{\text {wat-IL }}+d_{\text {wat-salt }}\right)$. Because the real partitioning occurs between IL and salt ions, the interface can alternatively be defined by the crossing of the density curves of IL and salt ions. Focusing on the interfaces of $\mathrm{D}, \mathrm{K}$, and $\mathrm{L}$ biphasic solutions (with $\mathrm{NaCl}, \mathrm{SrCl}_{2}$, and $\mathrm{EuCl}_{3}$ salts, respectively), one finds similar $\langle z\rangle_{\text {ITF }}$ positions from these 
two definitions: with the first one, the interface is shifted by only $\approx 0.3 \mathrm{~nm}$ from the second one, toward the IL-phase on the average. In the three solutions, the interface is rather sharp and narrow: defining its "width" by the distance between $z$ planes where the IL-density and the salt-density attain $90 \%$ of their values in the bulk adjacent phases, one obtains ca. 2.2, 1.6, and $1.2 \mathrm{~nm}$, respectively, for $\mathrm{NaCl}, \mathrm{SrCl}_{2}$, and $\mathrm{EuCl}_{3}$ containing ABSs. Thus, the more hydrophilic the metal salt is, the sharper and narrower is the interface. Snapshots (Figure 14) and density curves (Figure 5) show that there is more salt

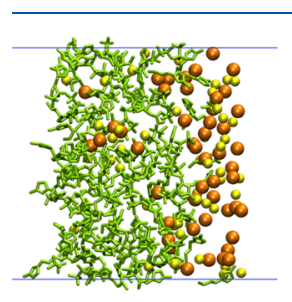

D

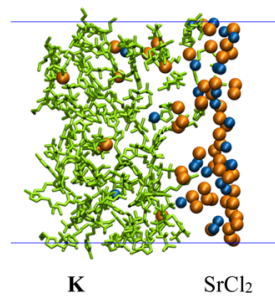

$\mathrm{SrCl}_{2}$

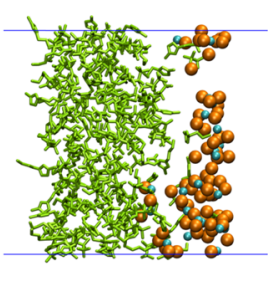

L
Figure 14. Snapshots of ions at IL/salt interfaces of biphasic solutions $\mathrm{D}, \mathrm{K}$, and $\mathrm{L}$ (slices of $3.5 \mathrm{~nm}$ width; water hidden for clarity). Color codes: $\mathrm{Cl}^{-}$orange, $\mathrm{Na}^{+}$yellow, $\mathrm{Sr}^{2+}$ dark blue, and $\mathrm{Eu}^{3+}$ cyan.

penetration on the IL side than IL penetration on the salt side of the interface. Near the interface, the IL density slope is much the same with the three salts, whereas the salt slope is weaker and decreases from $\mathrm{EuCl}_{3}$ to $\mathrm{NaCl}$. Comparing now these $\mathrm{ABS}$ interfaces to those of hydrophobic ILs/water solutions, the former ones are found to be comparable in size. The main difference with the studied ABSs is that the $\mathrm{BMI}^{+} \mathrm{TfO}^{-}$ions are better hydrated and that the cohesion forces of the IL phase are induced by the added hydrophilic salt and by water. On the other hand, neither the butyl chain of the $\mathrm{BMI}^{+}$cation nor the trifluoro group of the $\mathrm{TfO}^{-}$anion are long enough to induce organized structures like micelles in water. $^{86}$ The simulated interfaces can be viewed as zooms of "flat" ABSs at rest, as well as interfaces of IL droplets formed in the solutions, near the cloud point compositions.

\section{CONCLUSIONS}

We report MD simulations of concentrated aqueous mixtures of IL and $\mathrm{MCl}_{n}$ salt ions, selecting solutions that are experimentally monophasic and biphasic. They reveal in all cases collective phenomena yielding marked heterogeneities and segregation features into mutually exclusive neutral IL and salt domains ("ionic sociology"). These domains range, depending on the concentration, from locally fluctuating nanoregions (in monophasic solutions) to completely separated IL and salt aqueous phases (in ABSs). Segregation stems here from two main features: (i) IL ions tend to "attract" each other because of hydrophobic forces (dehydration of their apolar moieties) and to IL/IL attractions upon segregation. Even without added salt, the IL ions display significant anion... cation and anion $\cdots$ anion hydrophobic contacts. (ii) The salt ions trap water, by increasing amounts and at longer distances when their salting-out character (concentration and/or $\mathrm{M}^{n+}$ hydrophilicity) is increased. The water transfer from the IL to the salt ions can be viewed as a water-donor/water-acceptor synergistic process: $\mathrm{MCl}_{n}$ ions attract water (mainly in their second coordination shell and much beyond when the cationic charge increases), whereas IL ions release water from their hydrophobic moieties (up to ca. 50\% of first hydration shell in the presence of $\mathrm{MCl}_{n}$ salts), yielding an entropic gain. Consistent comparisons show that ion segregation and ABS formation increase with the salt concentration, the IL concentration, the $\mathrm{M}^{n+}$ charge, and the "polarity" of IL ions, in good agreement with experiment. In the ABSs, the aqueousIL/aqueous-salt interface is found to be quite sharp and of decreasing width when the dissolved $\mathrm{MCl}_{n}$ salt becomes more "salting-out". Finally, we point to analogies between ion "organization" in ABSs and the contrasting behavior of IL and $\mathrm{MCl}_{n}$ salts at aqueous interfaces and thus with the Hofmeister classification of IL and salt ions. From the analysis of snapshots, density curves, the "demixing index" $\xi_{\text {demix }}$ RDFs, and energy components, no clear-cut transition is observed, however, between heterogeneous monophasic systems and biphasic ones, calling for physical and simulation studies on nanoorganization in these phases as well as on their "cloud point" intermediate state, focusing on interactions and structuration at "long distances". Comparisons with other ILs (e.g., $[\mathrm{BMI}]\left[\mathrm{BF}_{4}\right]$ ) or related $\mathrm{ABSs}$ (e.g., with PEGs) combining dry ILs ${ }^{87}$ or "humid" ILs ${ }^{88}$ should enable further analysis of the specificity of the presently studied ones.

\section{ASSOCIATED CONTENT}

\section{Supporting Information}

The Supporting Information is available free of charge on the ACS Publications website at DOI: 10.1021/acs.jpcb.8b06193.

Description of all simulated systems; characteristics of RDFs; assignment of the different "phases"; final snapshots of the simulated systems with the $\mathrm{IL}^{ \pm 1}$ and $\mathrm{IL}^{ \pm 0.9}$ models; density curves along the $z$-axis; and extended results for the neat solution $\mathrm{A}$, for the aqueous $\mathrm{IL} /$ vacuum interface, and for the pure dry IL (PDF)

\section{AUTHOR INFORMATION}

\section{Corresponding Author}

*E-mail: wipff@unistra.fr (G.W.).

ORCID ${ }^{\circ}$

Georges Wipff: 0000-0002-3223-1845

Notes

The authors declare no competing financial interest.

\section{ACKNOWLEDGMENTS}

The authors are grateful to Alain Chaumont and Etienne Engler for assistance and useful discussions, to Jack Harrowfield for linguistic assistance, and to the Université de Strasbourg for computational resources. G.W. thanks Gérard Wipff for stimulating support.

\section{REFERENCES}

(1) Albertson, P.-A. Partition of Cell Particles and Macromolecules: Distribution and Fractionation of Cells, Viruses, Microsomes, Proteins. In Nucleic Acids, and Antigen-Antibody Complexes in Aqueous Polymer Two-Phase Systems; John Wiley \& Sons: New York, 1960.

(2) Iqbal, M.; Tao, Y.; Xie, S.; Zhu, Y.; Chen, D.; Wang, X.; Huang, L.; Peng, D.; Sattar, A.; Shabbir, M. A. B.; Hussain, H. I.; Ahmed, S.; Yuan, Z. Aqueous Two-Phase System (ATPS): an Overview and Advances in its Applications. Biol. Proced. Online 2016, 18, 18.

(3) Gutowski, K. E.; Broker, G. A.; Willauer, H. D.; Huddleston, J. G.; Swatloski, R. P.; Holbrey, J. D.; Rogers, R. D. Controlling the Aqueous Miscibility of Ionic Liquids: Aqueous Biphasic Systems of Water-Miscible Ionic Liquids and Water-Structuring Salts for Recycle, Metathesis, and Separations. J. Am. Chem. Soc. 2003, 125, 6632-6633. 
(4) Rogers, R. D.; Willauer, H. D.; Griffin, S. T.; Huddleston, J. G. Partitioning of Small Organic Molecules in Aqueous Biphasic Systems. J. Chromatogr. B: Biomed. Sci. Appl. 1998, 711, 255-263.

(5) Huddleston, J. G.; Willauer, H. D.; Griffin, S. T.; Rogers, R. D. Aqueous Polymeric Solutions as Environmentally Benign Liquid/ Liquid Extraction Media. Ind. Eng. Chem. Res. 1999, 38, 2523-2539.

(6) Freire, M. G.; Cláudio, A. F. M.; Araújo, J. M. M.; Coutinho, J. A. P.; Marrucho, I. M.; Lopes, J. N. C.; Rebelo, L. P. N. Aqueous Biphasic Systems: a Boost Brought about by Using Ionic Liquids. Chem. Soc. Rev. 2012, 41, 4966-4995.

(7) Lopes, J. N. C. ABS Composed of Ionic Liquids and Inorganic Salts. In Ionic-Liquid-Based Aqueous Biphasic Systems: Fundamentals and Applications; Freire, M. G., Ed.; Verlag: Springer Berlin Heidelberg, 2016; pp 27-35.

(8) Dupont, D.; Depuydt, D.; Binnemans, K. Overview of the Effect of Salts on Biphasic Ionic Liquid/Water Solvent Extraction Systems: Anion Exchange, Mutual Solubility, and Thermomorphic Properties. J. Phys. Chem. B 2015, 119, 6747-6757.

(9) Ventura, S. P. M.; Neves, C. M. S. S.; Freire, M. G.; Marrucho, I. M.; Oliveira, J.; Coutinho, J. A. P. Evaluation of Anion Influence on the Formation and Extraction Capacity of Ionic-Liquid-Based Aqueous Biphasic Systems. J. Phys. Chem. B 2009, 113, 9304-9310. (10) Neves, C. M. S. S.; Ventura, S. P. M.; Freire, M. G.; Marrucho, I. M.; Coutinho, J. A. P. Evaluation of Cation Influence on the Formation and Extraction Capability of Ionic-Liquid-Based Aqueous Biphasic Systems. J. Phys. Chem. B 2009, 113, 5194-5199.

(11) Tomé, L. I. N.; Varanda, F. R.; Freire, M. G.; Marrucho, I. M.; Coutinho, J. A. P. Towards an Understanding of the Mutual Solubilities of Water and Hydrophobic Ionic Liquids in the Presence of Salts: The Anion Effect. J. Phys. Chem. B 2009, 113, 2815-2825.

(12) Han, J.; Yu, C.; Wang, Y.; Xie, X.; Yan, Y.; Yin, G.; Guan, W. Liquid-Liquid Equilibria of Ionic Liquid 1-Butyl-3-Methylimidazolium Tetrafluoroborate and Sodium Citrate/Tartrate/Acetate Aqueous Two-Phase Systems at 298.15 K: Experiment and Correlation. Fluid Phase Equilib. 2010, 295, 93-103.

(13) Li, C.; Han, J.; Wang, Y.; Yan, Y.; Pan, J.; Xu, X.; Zhang, Z. Phase Behavior for the Aqueous Two-Phase Systems Containing the Ionic Liquid 1-Butyl-3-methylimidazolium Tetrafluoroborate and Kosmotropic Salts. J. Chem. Eng. Data 2010, 55, 1087-1092.

(14) Shahriari, S.; Neves, C. M. S. S.; Freire, M. G.; Coutinho, J. A. P. Role of the Hofmeister Series in the Formation of Ionic-LiquidBased Aqueous Biphasic Systems. J. Phys. Chem. B 2012, 116, 72527258.

(15) Hofmeister, F. Zur Lehre von der Wirkung der Salze. Arch. für Exp. Pathol. Pharmakol. 1888, 24, 247-260.

(16) Kunz, W.; Lo Nostro, P.; Ninham, B. W. The Present State of Affairs with Hofmeister Effects. Curr. Opin. Colloid Interface Sci. 2004, 9, 1-18.

(17) Jungwirth, P.; Cremer, P. S. Beyond Hofmeister. Nat. Chem. 2014, 6, 261-263.

(18) Bridges, N. J.; Rogers, R. D. Can Kosmotropic Salt/Chaotropic Ionic Liquid (Salt/Salt Aqueous Biphasic Systems) be Used to Remove Pertechnetate From Complex Salt Waste? Separ. Sci. Technol. 2008, 43, 1083-1090.

(19) Ranke, J.; Othman, A.; Fan, P.; Müller, A. Explaining Ionic Liquid Water Solubility in Terms of Cation and Anion Hydrophobicity. Int. J. Mol. Sci. 2009, 10, 1271-1289.

(20) Rebelo, L. P. N.; Najdanovic-Visak, V.; Visak, Z. P.; da Ponte, M. N.; Szydlowski, J.; Cerdeiriña, C. A.; Troncoso, J.; Romaní, L.; Esperança, J. M. S. S.; Guedes, H. J. R.; de Sousa, H. C. A detailed thermodynamic analysis of $[\mathrm{C} 4 \mathrm{mim}][\mathrm{BF} 4]+$ water as a case study to model ionic liquid aqueous solutions. Green Chem. 2004, 6, 369-381.

(21) Trindade, J. R.; Visak, Z. P.; Blesic, M.; Marrucho, I. M.; Coutinho, J. A. P.; Lopes, J. N. C.; Rebelo, L. P. N. Salting-Out Effects in Aqueous Ionic Liquid Solutions: Cloud-Point Temperature Shifts $\dagger$. J. Phys. Chem. B 2007, 111, 4737-4741.

(22) Bridges, N. J.; Gutowski, K. E.; Rogers, R. D. Investigation of Aqueous Biphasic Systems formed from Solutions of Chaotropic Salts with Kosmotropic Salts (Salt-Salt ABS). Green Chem. 2007, 9, 177183.

(23) Zhao, H. Are Ionic Liquids Kosmotropic or Chaotropic? An Evaluation of Available Thermodynamic Parameters for Quantifying the Ion Kosmotropicity of Ionic Liquids. J. Chem. Technol. Biotechnol. 2006, 81, 877-891.

(24) Zangi, R. Can Salting-In/Salting-Out Ions be Classified as Chaotropes/Kosmotropes? J. Phys. Chem. B 2010, 114, 643-650.

(25) Marcus, Y. Effect of Ions on the Structure of Water: Structure Making and Breaking. Chem. Rev. 2009, 109, 1346-1370.

(26) Freire, M. G.; Carvalho, P. J.; Silva, A. M. S.; Santos, L. M. N. B. F.; Rebelo, L. P. N.; Marrucho, I. M.; Coutinho, J. A. P. Ion Specific Effects on the Mutual Solubilities of Water and Hydrophobic Ionic Liquids. J. Phys. Chem. B 2009, 113, 202-211.

(27) Freire, M. G.; Neves, C. M. S. S.; Silva, A. M. S.; Santos, L. M. N. B. F.; Marrucho, I. M.; Rebelo, L. P. N.; Shah, J. K.; Maginn, E. J.; Coutinho, J. A. P. ${ }^{1} \mathrm{H}$ NMR and Molecular Dynamics Evidence for an Unexpected Interaction on the Origin of Salting-In/Salting-Out Phenomena. J. Phys. Chem. B 2010, 114, 2004.

(28) Zafarani-Moattar, M. T.; Hosseinpour-Hashemi, V. Effect of Temperature on the Aqueous Two-Phase System Containing Poly(ethylene glycol) Dimethyl Ether 2000 and Dipotassium Oxalate. J. Chem. Eng. Data 2012, 57, 532-540.

(29) da Silva, L. H. M.; Loh, W. Calorimetric Investigation of the Formation of Aqueous Two-Phase Systems in Ternary Mixtures of Water, Poly(ethylene oxide) and Electrolytes (Or Dextran). J. Phys. Chem. B 2000, 104, 10069-10073.

(30) Kurnia, K. A.; Freire, M. G.; Coutinho, J. A. P. Effect of Polyvalent Ions in the Formation of Ionic-Liquid-Based Aqueous Biphasic Systems. J. Phys. Chem. B 2014, 118, 297-308.

(31) Tomé, L. I. N.; Jorge, M.; Gomes, J. R. B.; Coutinho, J. A. P. Molecular Dynamics Simulation Studies of the Interactions between Ionic Liquids and Amino Acids in Aqueous Solution. J. Phys. Chem. B 2012, 116, 1831-1842.

(32) Sieffert, N.; Wipff, G. Adsorption at the Liquid-Liquid Interface in the Biphasic Rhodium-Catalyzed Hydroformylation of 1Hexene in Ionic Liquids: A Molecular Dynamics Study. J. Phys. Chem. C 2008, 112, 6450-6461.

(33) Chaumont, A.; Wipff, G. Strontium Nitrate Extraction to Ionic Liquids by a Crown Ether: A Molecular Dynamics Study of Aqueous Interfaces with $\mathrm{C} 4 \mathrm{mim}+-$ vs $\mathrm{C} 8 \mathrm{mim}+-\mathrm{Based}$ Ionic Liquids. J. Phys. Chem. B 2010, 114, 13773-13785.

(34) Endres, F. Interfaces of Ionic Liquids. Phys. Chem. Chem. Phys. 2012, 14, 5008-5009.

(35) Hantal, G.; Sega, M.; Kantorovich, S.; Schröder, C.; Jorge, M. Intrinsic Structure of the Interface of Partially Miscible Fluids: An Application to Ionic Liquids. J. Phys. Chem. C 2015, 119, 2844828461.

(36) Steinrück, H.-P. Recent Developments in the Study of Ionic Liquid Interfaces Using X-Ray Photoelectron Spectroscopy and Potential Future Directions. Phys. Chem. Chem. Phys. 2012, 14, 5010-5029.

(37) Aliaga, C.; Baldelli, S. Sum Frequency Generation Spectroscopy of Dicyanamide Based Room-Temperature Ionic Liquids. Orientation of the Cation and the Anion at the Gas-liquid Interface. J. Phys. Chem. B 2007, 111, 9733-9740.

(38) Case, D. A.; Cerutti, D. S.; Cheatham, T. E., III; Darden, T. A.; Duke, R. E.; Giese, T. J.; Gohlke, H.; Goetz, A. W.; Kollman, P. A.; et al. AMBER; University of California: San Francisco, 2017.

(39) Jorgensen, W. L.; Chandrasekhar, J.; Madura, J. D.; Impey, R. W.; Klein, M. L. Comparison of Simple Potential Functions for Simulating Liquid Water. J. Chem. Phys. 1983, 79, 926-935.

(40) Joung, I. S.; Cheatham, T. E., III Determination of Alkali and Halide Monovalent Ion Parameters for Use in Explicitly Solvated Biomolecular Simulations. J. Phys. Chem. B 2008, 112, 9020-9041.

(41) Åqvist, J. Ion-Water Interaction Potentials Derived from Free Energy Perturbation Simulations. J. Phys. Chem. 1990, 94, 80218024. 
(42) van Veggel, F. C. J. M.; Reinhoudt, D. N. New, Accurate Lennard-Jones Parameters for Trivalent Lanthanide Ions, Tested on [18]Crown-6. Chem.-Eur. J. 1999, 5, 90-95.

(43) de Andrade, J.; Böes, E. S.; Stassen, H. A Force Field for Liquid State Simulations on Room Temperature Molten Salts: 1-Ethyl-3methylimidazolium Tetrachloroaluminate. J. Phys. Chem. B 2002, 106, $3546-3548$

(44) Baaden, M.; Berny, F.; Madic, C.; Wipff, G. M3+Lanthanide Cation Solvation by Acetonitrile: The Role of Cation Size, Counterions, and Polarization Effects Investigated by Molecular Dynamics and Quantum Mechanical Simulations. J. Phys. Chem. A 2000, 104, 7659-7671.

(45) Chaumont, A.; Schurhammer, R.; Wipff, G. Aqueous Interfaces with Hydrophobic Room-Temperature Ionic Liquids: A Molecular Dynamics Study. J. Phys. Chem. B 2005, 109, 18964-18973.

(46) Sieffert, N.; Wipff, G. The $[\mathrm{BMI}]\left[\mathrm{Tf}_{2} \mathrm{~N}\right]$ Ionic Liquid/Water Binary System: A Molecular Dynamics Study of Phase Separation and of the Liquid-Liquid Interface. J. Phys. Chem. B 2006, 110, 1307613085 .

(47) Gaillard, C.; Mazan, V.; Georg, S.; Klimchuk, O.; Sypula, M.; Billard, I.; Schurhammer, R.; Wipff, G. Acid Extraction to a Hydrophobic Ionic Liquid: the Role of Added Tributylphosphate Investigated by Experiments and Simulations. Phys. Chem. Chem. Phys. 2012, 14, 5187-5199.

(48) Chevrot, G.; Schurhammer, R.; Wipff, G. Molecular dynamics simulations of the aqueous interface with the $[\mathrm{BMI}][\mathrm{PF} 6]$ ionic liquid: comparison of different solvent models. Phys. Chem. Chem. Phys. 2006, 8, 4166-4174.

(49) Bhargava, B. L.; Balasubramanian, S. Refined potential model for atomistic simulations of ionic liquid [bmim] [PF6]. J. Chem. Phys. 2007, 127, 114510 .

(50) Berendsen, H. J. C.; Postma, J. P. M.; van Gunsteren, W. F.; DiNola, A.; Haak, J. R. Molecular Dynamics with Coupling to an External Bath. J. Chem. Phys. 1984, 81, 3684-3690.

(51) Engler, E.; Wipff, G. MD-DRAW Software. Display of Dynamic Structures from MD Simulations. In Crystallography of Supramolecular Compounds; Tsoucaris, G., Ed.; Kluwer: Dordrecht, 1996; pp 471476.

(52) Humphrey, W.; Dalke, A.; Schulten, K. VMD: Visual molecular dynamics. J. Mol. Graphics 1996, 14, 33-38.

(53) Muzet, N.; Engler, E.; Wipff, G. Demixing of Binary WaterChloroform Mixtures Containing Ionophoric Solutes and Ion Recognition at a Liquid-Liquid Interface: A Molecular Dynamics Study. J. Phys. Chem. B 1998, 102, 10772-10788.

(54) Lynden-Bell, R. M.; Del Pópolo, M. G.; Youngs, T. G. A.; Kohanoff, J.; Hanke, C. G.; Harper, J. B.; Pinilla, C. C. Simulations of Ionic Liquids, Solutions, and Surfaces. Acc. Chem. Res. 2007, 40, $1138-1145$

(55) Lopes, J. N. C.; Pádua, A. A. H. Molecular Force Field for Ionic Liquids III: Imidazolium, Pyridinium, and Phosphonium Cations; Chloride, Bromide and Dicyanamide Anions. J. Phys. Chem. B 2006, 110, 19586-19592.

(56) Köddermann, T.; Paschek, D.; Ludwig, R. Molecular Dynamic Simulations of Ionic Liquids: a Reliable Description of Structure, Thermodynamics and Dynamics. ChemPhysChem 2007, 8, 24642470

(57) Lopes, J. N. C.; Pádua, A. A. H. Molecular Force Field for Ionic Liquids Composed of Triflate or Bistriflylimide Anions. J. Phys. Chem. B 2004, 108, 16893-16898.

(58) Sunda, A. P.; Venkatnathan, A. Molecular Dynamics Simulations of Triflic Acid and Triflate Ion/Water Mixtures: A Proton Conducting Electrolytic Component in Fuel Cells. J. Comput. Chem. 2011, 32, 3319-3328.

(59) Hünenberger, P.; Reif, M. Single-Ion Solvation: Experimental and Theoretical Approaches to Elusive Thermodynamic Quantities; RSC Pub.: London, 2011; p 300.

(60) Hunt, P. A.; Maginn, E. J.; Lynden-Bell, R. M.; Del Popolo, M. G., Computational Modeling of Ionic Liquids. In Ionic Liquids in Synthesis. 2nd ed., Completely Revised and enlarged Version;
Wasserscheid, P., Welton, T., Eds.; Wiley-VCH: Weinheim, 2007; Vol. 1, pp 206-249.

(61) Jungwirth, P.; Tobias, D. J. Specific Ion Effects at the Air/Water Interface. Chem. Rev. 2006, 106, 1259-1281.

(62) Baaden, M.; Schurhammer, R.; Wipff, G. Molecular Dynamics Study of the Uranyl Extraction by Tri-n-butylphosphate (TBP): Demixing of Water/“Oil”/TBP Solutions with a Comparison of Supercritical CO2and Chloroform. J. Phys. Chem. B 2002, 106, 434441

(63) Chevrot, G.; Schurhammer, R.; Wipff, G. Surfactant Behavior of “Ellipsoidal” Dicarbollide Anions: A Molecular Dynamics Study. J. Phys. Chem. B 2006, 110, 9488-9498.

(64) Matějíček, P.; Cígler, P.; Procházka, K.; Král, V. Molecular Assembly of Metallocarboranes in Water: Light Scattering and Microscopic Study. Langmuir 2006, 22, 575-581.

(65) Cacace, M. G.; Landau, E. M.; Ramsden, J. J. The Hofmeister series: salt and solvent effects on interfacial phenomena. Q. Rev. Biophys. 1997, 30, 241-277.

(66) Freire, M. G.; Louros, C. L. S.; Rebelo, L. P. N.; Coutinho, J. A. P. Aqueous Biphasic Systems Composed of a Water-Stable Ionic Liquid + Carbohydrates and their Applications. Green Chem. 2011, 13, 1536-1545.

(67) Marcus, Y. Ion Solvation; Wiley: Chichester, 1985.

(68) Jeffrey, G. A. Water Structure in Organic Hydrates. Acc. Chem. Res. 1969, 2, 344-352.

(69) Blokzijl, W.; Engberts, J. B. F. N. Hydrophobic Effects. Opinions and Facts. Angew. Chem., Int. Ed. Engl. 1993, 32, 15451579.

(70) Domínguez-Pérez, M.; Tomé, L. I. N.; Freire, M. G.; Marrucho, L. M.; Cabeza, O.; Coutinho, J. A. P. Extraction of Biomolecules using Aqueous Biphasic Systems Formed by Ionic Liquids and Aminoacids. Sep. Purif. Technol. 2010, 72, 85-91.

(71) Cammarata, L.; Kazarian, S. G.; Salter, P. A.; Welton, T. Molecular States of Water in Room Temperature Ionic Liquids Electronic Supplementary Information available. See http:// www.rsc.org/suppdata/cp/b1/b106900d/. Phys. Chem. Chem. Phys. 2001, 3, 5192-5200.

(72) Jiang, W.; Wang, Y.; Voth, G. A. Molecular Dynamics Simulation of Nanostructural Organization in Ionic Liquid/Water Mixtures. J. Phys. Chem. B 2007, 111, 4812-4818.

(73) Freire, M. G.; Neves, C. M. S. S.; Carvalho, P. J.; Gardas, R. L.; Fernandes, A. M.; Marrucho, I. M.; Santos, L. M. N. B. F.; Coutinho, J. A. P. Mutual Solubilities of Water and Hydrophobic Ionic Liquids. J. Phys. Chem. B 2007, 111, 13082-13089.

(74) Lopes, J. N. A. C.; Pádua, A. A. H. Nanostructural Organization in Ionic Liquids. J. Phys. Chem. B 2006, 110, 3330-3335.

(75) Chaumont, A.; Wipff, G. Solvation of "Big" Spherical Solutes in Room Temperature Ionic Liquids and at their Aqueous Interface: A Molecular Dynamics Simulation Study. J. Mol. Liq. 2007, 131-132, $36-47$.

(76) Picálek, J.; Minofar, B.; Kolafa, J.; Jungwirth, P. Aqueous Solutions of Ionic Liquids: Study of the Solution/Vapor Interface Using Molecular Dynamics Simulations. Phys. Chem. Chem. Phys. 2008, 10, 5765-5775.

(77) Chaumont, A.; Wipff, G. Polyoxometalate Keggin Anions at Aqueous Interfaces with Organic Solvents, Ionic Liquids, and Graphite: a Molecular Dynamics Study. J. Phys. Chem. C 2009, 113, 18233-18243.

(78) Bera, M. K.; Ellis, R. J.; Burton-Pye, B. P.; Antonio, M. R. Structural Aspects of Heteropolyacid Microemulsions. Phys. Chem. Chem. Phys. 2014, 16, 22566-22574.

(79) Bauduin, P.; Prevost, S.; Farràs, P.; Teixidor, F.; Diat, O.; Zemb, T. A Theta-Shaped Amphiphilic Cobaltabisdicarbollide Anion: Transition From Monolayer Vesicles to Micelles. Angew. Chem. 2011, $123,5410-5412$

(80) Chaumont, A.; Chevrot, G.; Galand, N.; Sieffert, N.; Schurhammer, R.; Wipff, G. Ions and their Complexes at LiquidLiquid Interfaces: Nanoscopic Views from MD simulations. In Solvent 
Extraction: Fundamentals and Applications. ISEC 2008 Proceedings; Moyer, B., Ed., 2008; pp 43-58.

(81) Lynden-Bell, R. M.; Kohanoff, J.; Del Popolo, M. G. Simulation of Interfaces between Room Temperature Ionic Liquids and other Liquids. Faraday Discuss. 2005, 129, 57.

(82) Chorny, I.; Benjamin, I. Hydration Shell Exchange Dynamics during Ion Transfer Across the Liquid/Liquid Interface. J. Phys. Chem. B 2005, 109, 16455-16462.

(83) Wick, C. D.; Dang, L. X. Recent advances in Understanding Transfer Ions Across Aqueous Interfaces. Chem. Phys. Lett. 2008, 458, $1-5$.

(84) Benjamin, I. Recombination, Dissociation, and Transport of Ion Pairs across the Liquid/Liquid Interface. Implications for Phase Transfer Catalysis. J. Phys. Chem. B 2013, 117, 4325-4331.

(85) Palchowdhury, S.; Bhargava, B. L. Ionic Liquids at NonaneWater Interfaces: Molecular Dynamics Studies. J. Phys. Chem. B 2014, 118, 13930-13939.

(86) Freire, M. G.; Neves, C. M. S. S.; Lopes, J. N. C.; Marrucho, I. M.; Coutinho, J. A. P.; Rebelo, L. P. N. Impact of Self-Aggregation on the Formation of Ionic-Liquid-Based Aqueous Biphasic Systems. J. Phys. Chem. B 2012, 116, 7660-7668.

(87) Neves, C. M. S. S.; Shahriari, S.; Lemus, J.; Pereira, J. F. B.; Freire, M. G.; Coutinho, J. A. P. Aqueous Biphasic Systems Composed of Ionic Liquids and Polypropylene Glycol: Insights into their Liquid-Liquid Demixing Mechanisms. Phys. Chem. Chem. Phys. 2016, 18, 20571-20582.

(88) Cláudio, A. F. M.; Pereira, J. F. B.; McCrary, P. D.; Freire, M. G.; Coutinho, J. A. P.; Rogers, R. D. A Critical Assessment of the Mechanisms Governing the Formation of Aqueous Biphasic Systems Composed of Protic Ionic Liquids and Polyethylene Glycol. Phys. Chem. Chem. Phys. 2016, 18, 30009-30019. 